\title{
Revealing Vertical Distribution of Precipitation in the Glacierized Upper Indus Basin Based on Multiple Datasets $\mathscr{0}$
}

\author{
MuHAMMAD SHAFEEQUE \\ Key Lab of Ecosystem Network Observation and Modelling, Institute of Geographic Sciences and Natural Resources \\ Research, Chinese Academy of Sciences, and University of Chinese Academy of Sciences, Beijing, China \\ YI LUO \\ Key Lab of Ecosystem Network Observation and Modelling, Institute of Geographic Sciences and Natural Resources \\ Research, Chinese Academy of Sciences, and University of Chinese Academy of Sciences, Beijing, and \\ CAS Research Center for Ecology and Environment of Central Asia, Urumqi, China

\section{XiAOLEI WANG} \\ Key Lab of Ecosystem Network Observation and Modelling, Institute of Geographic Sciences and Natural Resources \\ Research, Chinese Academy of Sciences, Beijing, China

\section{LIN SUN} \\ Key Lab of Ecosystem Network Observation and Modelling, Institute of Geographic Sciences and Natural Resources \\ Research, Chinese Academy of Sciences, and University of Chinese Academy of Sciences, Beijing, China
}

(Manuscript received 10 April 2019, in final form 29 August 2019)

\begin{abstract}
The quality and vertical distribution of precipitation are of utmost importance in hydrological modeling studies in glacierized catchments, which have been facing known challenges in the quality, distribution, and magnitude of observed as well as gridded precipitation due to complex topography. The purpose of the study is to reveal the vertical distribution of precipitation based on multiple datasets and evaluate the suitability of these datasets for hydrological applications and in the upper Indus basin (UIB). The performance of five gridded precipitation datasets, that is, APHRODITE, CFSR, Princeton Global Meteorological Forcing Dataset for Land Surface Modeling (PGMFD), TRMM, and High Asia Refined analysis (HAR), was evaluated against the observed precipitation (OBS) during 2001-07. A corrected reference precipitation dataset was constructed based on the water and mass balance using inverse modeling methods. TRMM was identified as the best dataset to represent the spatial and temporal distribution of OBS precipitation. The runoff coefficients for OBS, APHRODITE, TRMM, and PGMFD were greater than 1, indicating that these datasets were underestimated and unable to close the water balance in UIB. The mean annual corrected precipitation was estimated as $593 \mathrm{~mm} \mathrm{yr}^{-1}$, while the main water-producing elevation zone was located between 3900 and $6600 \mathrm{~m}$. CFSR had the highest correlation and lowest bias with corrected precipitation along the vertical profile. It is concluded that the OBS and most of the gridded precipitation are insufficient to sustain the water and mass balance in UIB. It is recommended to correct the precipitation based on mass balance at high altitudes (especially along the main water-producing zone) in glacierized catchments before its application in hydrological modeling studies.
\end{abstract}

Supplemental information related to this paper is available at the Journals Online website: https://doi.org/10.1175/JHM-D-190081.s1.

Corresponding author: Yi Luo, luoyi@igsnrr.ac.cn

\section{Introduction}

Glacierized catchments are the main source of water to fulfill high water demands for domestic, agriculture, industries, and hydropower generation in downstream arid areas. The importance and uncertainty of water resources under climate change in glacierized catchments makes them climate change hotspots (De Souza 
et al. 2015). Hydrological modeling is the only key to assess the impacts of climate change on water resources for proper management, mitigation, and adaptation in these areas. Precipitation is the main parameter to force the hydrological models as the hydrological cycle heavily depends on the horizontal and vertical distribution of precipitation in glacierized mountain areas. The highaltitude precipitation plays the cutting-edge role in maintaining such meltwater-dependent hydrological systems and regimes, whereas the distribution and magnitude of precipitation at higher elevations are still unknown and not fully understood (Mishra 2015; Ragettli and Pellicciotti 2012; Winiger et al. 2005). The upper Indus basin (UIB) feeds the world's largest irrigation system and fast-growing population (Lutz et al. 2016). The UIB has been facing challenges of meteorological data scarcity and quality in addition to severe impacts of climate change. Many gridded datasets with varying spatial and temporal resolutions are available (Sun et al. 2018), but their credibility to be applied in glacierized mountain areas is questionable (Wortmann et al. 2018). The complex orographic effects, which result due to interactions between elevation and climate, and scarcity of good quality meteorological data limit our understanding of climate change impacts on water availability in glacierized mountain areas.

The observed precipitation data are scarce, discrepant, discontinuous, and heterogeneously distributed in UIB. Meteorological stations may provide more accurate local information, but their spatial representation is dubious (Tustison et al. 2001), especially in UIB, where precipitation varies based on ridge-valley precipitation gradients (Anders et al. 2006; Barros et al. 2004; Bhatt and Nakamura 2005). It is challenging to understand the spatial and temporal variability in mountainous regions because a single meteorological station cannot represent horizontal and vertical variability at the larger scales while the strong local ridge-valley gradients are difficult to capture by point measurements (Lutz et al. 2014a). Several gridded precipitation datasets have been produced based on interpolated observations, satellite-based data, and reanalysis data (e.g., Dee et al. 2011; Harris et al. 2014; Huffman et al. 2007; Yatagai et al. 2012) to overcome such issues. Gridded precipitation datasets can 1) provide information on precipitation conditions in the regions where networks of meteorological stations are sparse (Raimonet et al. 2017; Wortmann et al. 2018), 2) bridge the spatiotemporal gaps in data, and 3) potentially assist us to better understand the hydrological cycle. The gridded precipitation datasets are of coarser resolution and insufficient quality to represent the spatiotemporal variations and magnitude of precipitation over complex topography of glacierized catchments (Immerzeel et al. 2015), particularly, when spatial variability of precipitation is smaller than the resolution of the gridded dataset. The reliability of calibration and regionalization of hydrological models is highly influenced by the errors and biases in precipitation data (Renard et al. 2010) to confound attempts to simulate the impacts of climate change on water resources (Mendoza et al. 2016). Thus, uncertainties, biases, and spatiotemporal distribution of precipitation in gridded datasets have broader operational and scientific implications. The biases and errors in the gridded precipitation datasets are usually owing to inadequacies in the data sources and generation mechanisms of these products (Sun et al. 2018). The suitability of gridded precipitation datasets must be assessed against a reasonable dataset before using them for hydrological modeling to appraise the impacts of climate change on water resources in glacierized catchments.

In UIB, the complicated interplay between valleyscale topography-atmosphere interaction and synopticscale circulation defines the annual precipitation patterns (Barros et al. 2004; Hewitt 2014). The westerlies during the winter and southeastern monsoon during summer generate annual precipitation at synoptic scale (Mölg et al. 2014; Scherler et al. 2011) while the relative contributions of westerlies increase from southeast to northwest. The spatial distribution of precipitation is controlled by the interactions between topography and atmosphere in different zones (Bookhagen and Burbank 2006; Immerzeel et al. 2014). The valley bottoms are drier than the higher elevations, and precipitation increases up to a certain altitude and then starts decreasing due to forced orographic removal of moisture from the air. The altitude of maximum precipitation is higher in the westerlies-dominated precipitation zones than that in monsoon-dominated zones because of the higher tropospheric altitude of westerly airflow (Hewitt 2007; Scherler et al. 2011; Winiger et al. 2005). In most of the catchments with complex terrain and sparse gauge network, the ground truth data is unreliable or unavailable; therefore, the estimation of uncertainty or bias is challenging in such cases (Henn et al. 2018). The observed precipitation is mostly unavailable at high altitudes and underestimated at higher elevation stations (above $4000 \mathrm{~m}$ MSL), which are usually located in the dry valleys. In such circumstances, a reference dataset is needed with orographically corrected precipitation at high altitudes to evaluate and find out the suitable gridded precipitation dataset for hydrological applications in glacierized UIB.

The orographic correction of precipitation is necessary to generate an accurate precipitation dataset in high mountain catchments (Immerzeel et al. 2014; Stisen et al. 2012) for different uses, for example, using to evaluate or validate other precipitation datasets as well as directly apply in hydrological modeling. The correction factors and precipitation gradients along the vertical profile have been calculated using mass balance information or 
assuming near-glacier equilibrium (Immerzeel et al. 2012, 2015; Wortmann et al. 2018). Linear gradients were also used to vary the precipitation along the vertical profile ranging from $0.05 \%$ to $0.5 \% \mathrm{~m}^{-1}$ in complex terrains (Hock and Holmgren 2005; Immerzeel et al. 2014). Assessing precipitation variations as a linear function of elevation is highly variable over different altitudes and unsuitable to represent the elevations below the reference elevation because precipitation might become zero or even negative (Wortmann et al. 2018). In UIB, the mass balance data can contain critical hydrological information because the glaciers are located at higher elevations and cannot be represented by low-elevation station precipitation. Immerzeel et al. (2015) generated high elevation precipitation using glacier mass balance data and showed that the amount of precipitation is underestimated in observed and gridded products; moreover, these datasets cannot sustain the observed mass balance. Wortmann et al. (2018) proposed a continuous function to correct the precipitation based on the mass balance in headwaters of the Tarim River basin and claimed that this function could be applied to any other glacierized catchment. The application of correction function proposed by Wortmann et al. (2018) to correct the precipitation might be useful in UIB, but its validation in this area is unknown. Immerzeel et al. (2015) and Wortmann et al. (2018) used Asian Precipitation-Highly Resolved Observational Data Integration Toward Evaluation of Water Resources (APHRODITE) precipitation as a base for orographic precipitation correction. However, it has been argued that APHRODITE dataset does not represent the spatial and temporal patterns of precipitation well in UIB (Dahri et al. 2016). Therefore, it is all-important that multiple gridded precipitation datasets, based on different sources and mechanisms of generation, should be evaluated against observed spatial and temporal patterns of precipitation. Then, the most appropriate gridded dataset, which represents the spatial and temporal patterns of observations, should be used in the precipitation correction process.

The current study is conducted keeping in mind the hydrological applications to create awareness about uncertainties and biases in gridded precipitation datasets in glacierized catchments with complex topography. The main objectives of the current study are 1) systematic evaluation of differences and performance of gridded precipitation datasets to make researchers aware of the amount of uncertainty and biases in these datasets, 2) to reveal the vertical distribution of precipitation based on multiple precipitation datasets in UIB. First, the performance of five gridded precipitation datasets, that is, APHRODITE (APHRO hereafter; Yatagai et al. 2012), Climate Forecast System Reanalysis (CFSR; Saha et al. 2010), Princeton Global Meteorological Forcing Dataset for Land Surface Modeling (PGMFD; Sheffield et al. 2006), Tropical Rainfall Measuring Mission (TRMM; Huffman and Bolvin 2015), and High Asia Refined analysis (HAR; Maussion et al. 2014), is evaluated against the observed precipitation (OBS) for an overlapped period 2001-07 at monthly, seasonal, and annual scales. Then, the ability of precipitation datasets, including OBS to reproduce the water balance is tested. After that, a corrected reference precipitation dataset is constructed based on the water and mass balance in UIB. Then, the horizontal and vertical distribution of precipitation are revealed. Finally, the suitability and physical realism or correctness of datasets for hydrological modeling studies are assessed. The outcomes of the study improve the understanding of the performance and vertical distribution of precipitation based on multiple datasets, and have implications in selection, improvement, and application of gridded precipitation in hydrological studies, especially in glacierized catchments.

\section{Materials and methods}

\section{a. Study area}

The UIB covers an area of $173213 \mathrm{~km}^{2}$, which is located in the political boundaries of China, India, and Pakistan, spanning $31^{\circ}-37^{\circ} \mathrm{N}$ and $72^{\circ}-82^{\circ} \mathrm{E}$ (Fig. 1). Around $46 \%$ of UIB falls within the political boundary of Pakistan. The eastern Hindu Kush range, Karakoram range, and western Himalayas are hosted by UIB. The Indus River starts from Kailash Valley in the western Tibetan Plateau at an elevation of about $5300 \mathrm{~m}$ MSL. It flows in a northwest direction, straddling three high mountain ranges: Himalayas, Karakorum, and Hindu Kush. Then, it turns toward the south, entering into foothills, and runs from the north to the south of Pakistan all the way to the Arabian Sea, with a total length of more than $3000 \mathrm{~km}$ (Inman 2010; Khan et al. 2015; Mukhopadhyay and Khan 2014). The basin area of the Indus River is about 1.1 million $\mathrm{km}^{2}$. This study is confined only to the UIB, which is the source region of the Indus River.

The UIB is known for its remarkable glaciers and snow-covered peaks, with 11413 glaciers having $15062 \mathrm{~km}^{2}$ glacier area (Bajracharya and Shrestha 2011). The main famous glaciers in UIB include the Batura, Baltoro, Siachen, Baifo, and Hispar glaciers, among others. The snow cover varies between $3 \%$ and $67 \%$ of total UIB area (Hasson et al. 2014). Maximum snow cover is recorded in March while the minimum is from July to September (Khan et al. 2015).

Based on the mountain ranges and mass balance behavior, the UIB (Fig. 1a) was divided into six zones (Fig. 1b). Each zone contains one or more or a part of the subbasins in UIB. The details on the zones are provided in Table 1. 


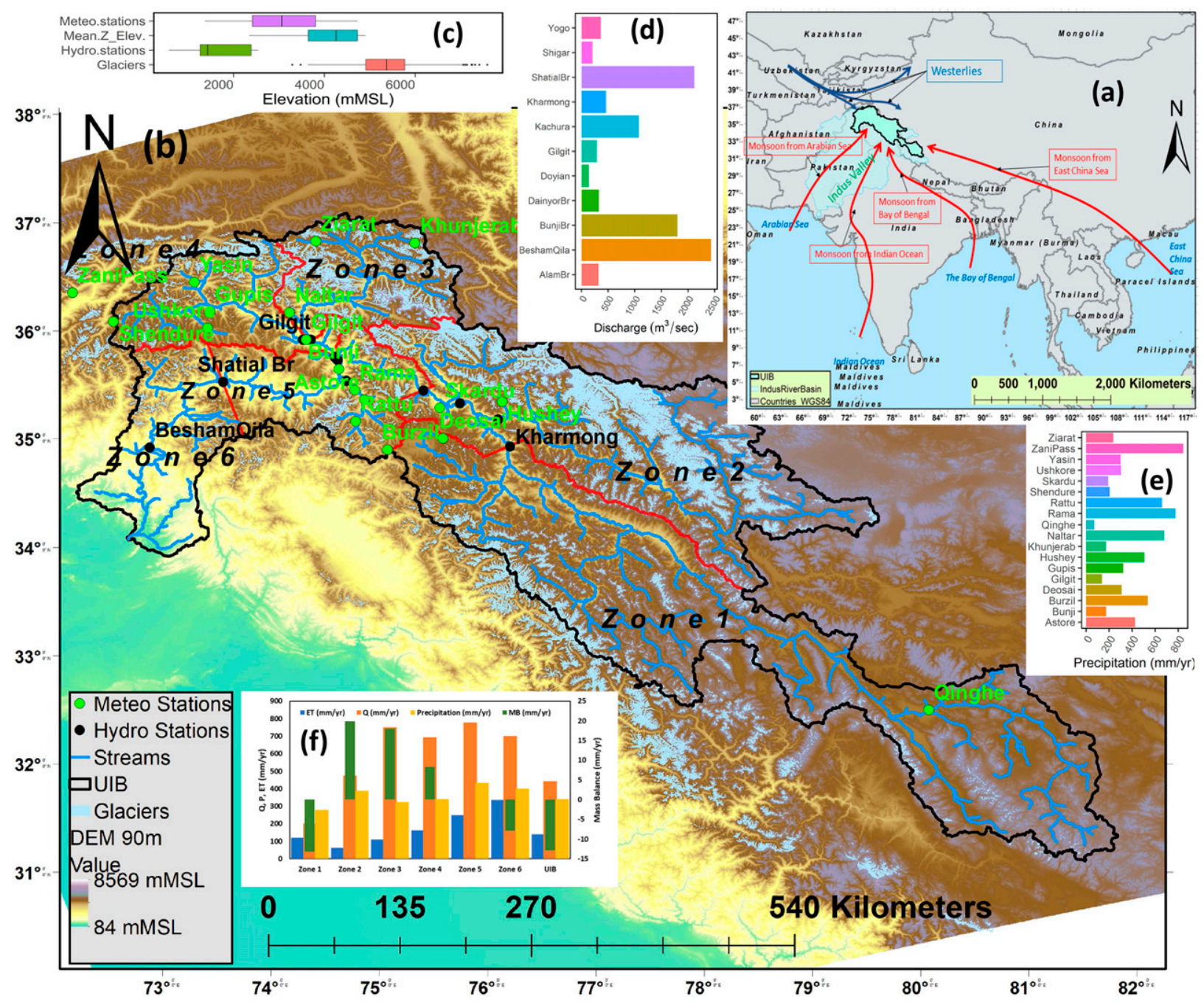

FIG. 1. (a) Geographical location of UIB and precipitation trajectories (path of moisture transport from the source to study area). (b) Location of six zones, stream network, meteorological stations, hydrological stations, and glaciers in the UIB. (c) Boxplots for the mean elevation of six zones, elevation of meteorological stations, hydrological stations, and glacier hypsometry. (d) Average discharge at hydrological stations. (e) Mean annual observed precipitation at different meteorological stations. (f) Average values of water balance components in six zones as well as the entire UIB.

The climate of the Indus basin is characterized by the South Asian summer monsoon atmospheric circulations and winter extratropical cyclonic/anticyclonic circulations (westerlies) around troughs of low/high pressure areas. Both the monsoon and westerlies influence the climatic pattern of UIB, and most of the precipitation occurs during winter. In the Karakorum, $67 \%$ of annual precipitation occurs in winter due to westerlies and the remaining is due to summer monsoons (Hewitt 2007). The differential heating between sea and land during summer causes the summer monsoon. The monsoon carries moisture from (i) the Bay of Bengal moving northward to the eastern Himalayas and Tibetan Plateau along the Brahmaputra River valley, (ii) the Arabian
Sea along the Indus valley to the western Himalaya, and (iii) the Indian Ocean after crossing southern India and then along the Indus River valley to the western Himalayas (Ahmad et al. 2012; Palazzi et al. 2013; Pang et al. 2014). The summer monsoon extends from July to September in the Indus basin. An extratropical frontal system causes the transport of moisture from the Mediterranean and the Caspian Sea via western disturbances in winter and early spring (Filippi et al. 2014; Mayer et al. 2014). In the northwest of UIB, westerlies enter during late November with distorted structure and diffused state and interact with the pre-existing orographic trough with low pressure and then regain their frontal structure and strength. The topographic blocking 
TABLE 1. Basic details of UIB and division of the whole catchment into different zones. The asterisks indicate that the UIB main stream subbasin was divided into four parts and then added into other subbasins for creating new zones.

\begin{tabular}{|c|c|c|c|c|c|c|c|}
\hline Zone & Catchments & $\begin{array}{l}\text { Area } \\
\left(\mathrm{km}^{2}\right)\end{array}$ & $\begin{array}{c}\text { Mean } \\
\text { elevation } \\
(\mathrm{m} \text { MSL) }\end{array}$ & $\begin{array}{c}\text { Glacier } \\
\text { area } \\
\left(\mathrm{km}^{2}\right)\end{array}$ & $\begin{array}{c}\text { Glacier } \\
\text { area ratio } \\
(\%)\end{array}$ & $\begin{array}{l}\text { Discharge } \\
\text { gauge }\end{array}$ & Discharge calculation \\
\hline Zone 1 & Zanskar, Shingo, UIB sub1\&2* & 71372.25 & 4800 & 2092.66 & 2.93 & Kharamong & Kharamong \\
\hline Zone 2 & Shyok, Shigar, UIB sub2b* & 43919.16 & 4908 & 7932.43 & 18.06 & Kachura & Kachura - Kharamong \\
\hline Zone 3 & Hunza & 13734.15 & 4515 & 2753.88 & 20.05 & Dainyor & Dainyor \\
\hline Zone 4 & Gilgit & 13540.35 & 4005 & 940.28 & 6.94 & Alam Bridge & Alam Bridge - Dainyor \\
\hline Zone 5 & Astore, UIB sub3* & 14758.72 & 3527 & 824.63 & 5.59 & Shatial Bridge & $\begin{array}{c}\text { Shatial Bridge - Alam } \\
\text { Bridge - Kachura }\end{array}$ \\
\hline Zone 6 & UIB sub4* & 16111.34 & 2343 & 284.23 & 1.76 & Bisham Qila & $\begin{array}{l}\text { Bisham Qila - Shatial } \\
\text { Bridge }\end{array}$ \\
\hline UIB & UIB & 173436 & 4402 & 14828.12 & 8.55 & Bisham Qila & Bisham Qila \\
\hline
\end{tabular}

bifurcates these westerlies into northern and southern branches around the Karakorum and western Tibetan Plateau. The water transported by the southern branch is the main cause of winter precipitation in UIB (Dahri et al. 2016; Pang et al. 2014). Sometimes, from the eastern end, the East Asian monsoon also enters into the study area in the Ladakh region (Dahri et al. 2016; Wang and Lin 2002). The interplay and interactions of local climate and topography with circulation systems determine the distribution pattern and amount of precipitation in UIB.

Significant seasonal variability is found in the streamflow of the Indus basin. The mean discharge at Besham Qila is $2405 \mathrm{~m}^{3} \mathrm{~s}^{-1}$ (Hasson et al. 2017). More than $70 \%$ of flow occurs from June to August, with maximum values in July (Khan et al. 2015). OctoberMarch are characterized as low-flow months, and after this dry period, the earliest supply of water is generated due to snowmelt from late May to late July depending on the accumulated snow and concurrent temperatures (Hasson et al. 2014). From late June to late August, the glacier melt joins the snowmelt depending on the melt season temperatures (Lutz et al. 2016). The snowmelt and glacier melt contribute more than $70 \%$ to mean annual streamflow in the Indus basin (Hasson et al. 2017; Lutz et al. 2014b; Mukhopadhyay and Khan 2014).

\section{b. Data collection}

\section{1) OBSERVED CLIMATE AND HYDRology DATA}

Meteorological data were collected from 18 meteorological stations (Figs. 1b,e) operated by the Pakistan Meteorological Department (PMD), Water and Power Development Authority (WAPDA) of Pakistan, and China Meteorological Data Sharing Network (CMDSN). Most of the meteorological stations are limited to the political boundary of Pakistan. Five valley-based stations have long-term records ( $>50$ years) and are maintained by PMD. Twelve automatic weather stations (AWS), which are called data collection platforms (DCPs), have data for more than 20 years since 1994. The meteorological station located within the political boundary of China has more than 50 years of data (Table 2).

The discharge data were collected from WAPDA at 10 different hydrological stations (Fig. 1b). The average values of discharge are provided in Fig. 1d. The discharge station and conceptual calculations of discharge for each zone are described in Table 1.

\section{2) GRIDDED PRECIPITATION DATASETS}

There are several gridded climatic products at regional and global scale derived using various means to use in climatic and hydrological assessment studies. Generally, such products are classified into four major categories: (i) derived from observed station data, (ii) climate models' reanalysis databases, (iii) a combination of observed station and reanalysis data, and (iv) based on satellite estimates. Table 3 gives a short overview of the selected datasets and their horizontal resolution, as well as the covered period. The main criteria for the selection of datasets were 1) good cross-section of their sources and methods of generation, 2) ease of accessibility and availability as final products in published datasets, 3) possible appropriateness for regional-scale applications, and 4) potential usefulness for hydrological modeling studies. APHRO is based on station observations, CSFR is based on reanalysis data, PGMFD is a combination of observations and reanalysis data, TRMM is based on satellite estimates calibrated with observations, and HAR is a downscaled reanalysis dataset validated with observations and satellite estimates. TRMM has been identified as the better dataset compared to other satellite precipitation products in the Indian monsoon, Tibet, and Himalayan region based on the summary of validation studies (Maggioni et al. 2016). Therefore, only TRMM was selected as a satellite 
TABLE 2. Details of meteorological stations in UIB. The number of years is counted, excluding the missing data years.

\begin{tabular}{|c|c|c|c|c|c|c|c|}
\hline Station No. & Station & Agency & Latitude $\left({ }^{\circ} \mathrm{N}\right)$ & Longitude $\left({ }^{\circ} \mathrm{E}\right)$ & Altitude (m) & Period & No. of years \\
\hline 1 & Astore & PMD & 35.366 & 74.865 & 2168 & 1954-2010 & 57 \\
\hline 2 & Bunji & PMD & 35.646 & 74.629 & 1372 & $1953-2010$ & 58 \\
\hline 3 & Burzil & WAPDA & 34.899 & 75.079 & 4239 & $1995-2015$ & 21 \\
\hline 4 & Deosai & WAPDA & 35.004 & 75.592 & 4149 & $2000-15$ & 16 \\
\hline 5 & Gilgit & PMD & 35.921 & 74.327 & 1460 & $1951-2010$ & 60 \\
\hline 6 & Gupis & PMD & 36.179 & 73.439 & 2156 & $1955-2010$ & 56 \\
\hline 7 & Hushey & WAPDA & 35.342 & 76.139 & 3075 & 1994-2007 & 11 \\
\hline 8 & Khunjrab & WAPDA & 36.812 & 75.332 & 4730 & $2000-15$ & 16 \\
\hline 9 & Naltar & WAPDA & 36.168 & 74.175 & 2898 & 1999-2011 & 13 \\
\hline 10 & Rama & WAPDA & 35.455 & 74.776 & 3179 & 1999-2008 & 10 \\
\hline 11 & Rattu & WAPDA & 35.161 & 74.785 & 2718 & $1995-2015$ & 21 \\
\hline 12 & Shendure & WAPDA & 36.088 & 72.547 & 3712 & $1995-2015$ & 19 \\
\hline 13 & Skardu & PMD & 35.286 & 75.563 & 2317 & $1952-2010$ & 59 \\
\hline 14 & Ushkore & WAPDA & 36.027 & 73.415 & 3051 & 1999-2015 & 17 \\
\hline 15 & Yasin & WAPDA & 36.451 & 73.294 & 3280 & 1999-2015 & 16 \\
\hline 16 & Zani Pass & WAPDA & 36.352 & 72.169 & 3839 & 1999-2007 & 13 \\
\hline 17 & Ziarat & WAPDA & 36.829 & 74.418 & 3020 & 1999-2015 & 15 \\
\hline 18 & Qinghe & CMDSN & 32.500 & 80.080 & 4279 & $1962-2012$ & 51 \\
\hline
\end{tabular}

product for the analysis. The other deeper details on these datasets are referred to in the cited references (Table 3).

\section{3) EVAPOTRANSPIRATION DATA}

The potential evapotranspiration data (Fig. 2a) were extracted from Global Reference Evapotranspiration (Global-ET0) at 1-km resolution over the period 1970-2000 (Antonio and Zomer 2018), available at the CGIAR-CSI GeoPortal. In this product, the potential evapotranspiration data were estimated based on the FAO Penman-Monteith method (Antonio and Zomer 2018).

The actual evapotranspiration data (Fig. 2b) were extracted from Esri_hydro "average annual actual evapotranspiration" derived by the researchers at the University of Montana based on the data from MOD16 Global Evapotranspiration Product (ESRI 2019). Pritchard (2017) argued that evaporation is less sensitive to precipitation datasets; therefore, a different dataset for actual ET other than precipitation is justified here. The actual ET layer with a raster cell size of $1 \mathrm{~km}$ provides annual evaporative loss from the land surface, measured in millimeters per year over the period 2000-14.

\section{4) Mass balance DATA}

The values for mass balance were estimated based on available literature. The glacier mass balance in UIB is very uncertain and difficult to estimate as there is no agreement among the available literature on either the amount of increase or decrease. UIB spans over the Himalayan, Karakorum, and Hindu Kush mountain ranges, and each mountain range has its unique behavior in terms of mass balance.

For zone 1 , an average value of $-0.45 \mathrm{~m}$ w.e. $\mathrm{yr}^{-1}$ (where w.e. is water equivalent) was assigned, based on the mass balance for the west Himalayas (Gardelle et al. 2013). For the parts of the UIB located in the Karakorum, zone 3 (Hunza) in west Karakorum and zone 2 (Shigar and Shyok) in the east Karakorum, the glacier mass balances are assumed to have a net positive trend and were allocated a value of +0.09 and $+0.11 \mathrm{~m}$ w.e. $\mathrm{yr}^{-1}$, respectively, as proposed by Gardelle et al. (2013). Zone 4 (the Gilgit watershed), located over the northern end of the Hindu Kush range, and the area below the Shatial bridge (zone 6 ) were assigned mass balance values as +0.12 and $-0.42 \mathrm{~m}$ w.e. $\mathrm{yr}^{-1}$ after Gardelle et al. (2013) and Brun et al. (2017), respectively. For zone 5, the glacier mass balance was taken as neutral. The glacier mass balance amounts for the different regions were converted from meters water equivalent per year $\left(\mathrm{m} \mathrm{w}\right.$ e. $\left.\mathrm{yr}^{-1}\right)$ to glacier storage changes in millimeter depth $(\mathrm{mm})$.

\section{c. Performance evaluation}

The performance of gridded precipitation was evaluated against the observations for an overlapped period 2001-07 at monthly, seasonal, and annual scale. There are several approaches available to evaluate the performance of gridded precipitation datasets against the observed precipitation. The first approach is to upscale the observed precipitation to generate a gridded dataset at the corresponding spatial resolution of gridded precipitation datasets (Dinku et al. 2008; Gampe and Ludwig 2017; Xu et al. 2015; Zhao and Fu 2006). However, enough meteorological stations are required to 
generate such a gridded dataset based on observations at high resolution because the fine-scaled processes cannot be resolved by coarser grids (Prein et al. 2016). The second approach is to downscale the gridded datasets to compare with the observed precipitation (Gao and Liu 2013). It has been argued that outputs of such upscaling or downscaling might suffer from large errors and uncertainties (Li and Heap 2011; Scheel et al. 2011). A third approach (direct comparison) has been proposed to overcome the uncertainties arising from upscaling or downscaling (Blacutt et al. 2015; Ma et al. 2009; Ward et al. 2011). In the direct comparison approach, single station precipitation or average of all the stations falling within a grid cell are compared to the respective grid of gridded dataset. This direct comparison approach is considered the most suitable approach because it avoids the uncertainties induced by upscaling or downscaling (Hu and Chen 2018; Hu et al. 2016), especially in the regions where meteorological stations are sparse and unequally distributed (Salio et al. 2015). In UIB, a small number of meteorological stations with unequal distribution, complex topography, and multifaceted precipitation systems make the third approach the best option for evaluating the performance of gridded datasets at different spatial and temporal scales. A sensitivity analysis was performed to identify the expected uncertainty under upscaling and downscaling approaches. Details are provided in the online supplemental material.

The gridded precipitation datasets were also compared against the observed discharge based on runoff coefficients to evaluate their ability to close the water balance in different zones of UIB.

\section{d. Precipitation correction and vertical distribution}

A reference dataset was generated based on water and mass balance to compare the vertical distributions and actual bias of precipitation in different datasets with the actual precipitation in UIB. All the calculations and modeling in this section were done in the raster environment using Climate Data Operators (CDO), ArcGIS v10.2, and R v3.4.4. The flowchart of the procedure for precipitation correction is provided in the Fig. 3.

In the first step, the true precipitation $\left(P_{T}\right)$ was estimated based on water balance in UIB. The observed discharge $(Q)$, actual evapotranspiration $\left(\mathrm{ET}_{a}\right)$, and the mass balance $(\mathrm{MB})$ data were used to close the water balance for true precipitation. The units used in Eq. (1) are millimeters per year:

$$
P_{T}=Q+\mathrm{ET}_{a}+\mathrm{MB}
$$

The data used in Eq. (1) may have some extent of uncertainty; therefore, a sensitivity analysis was performed to 

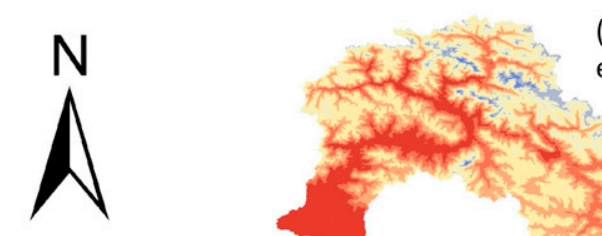

(a) Potential evapotranspiration

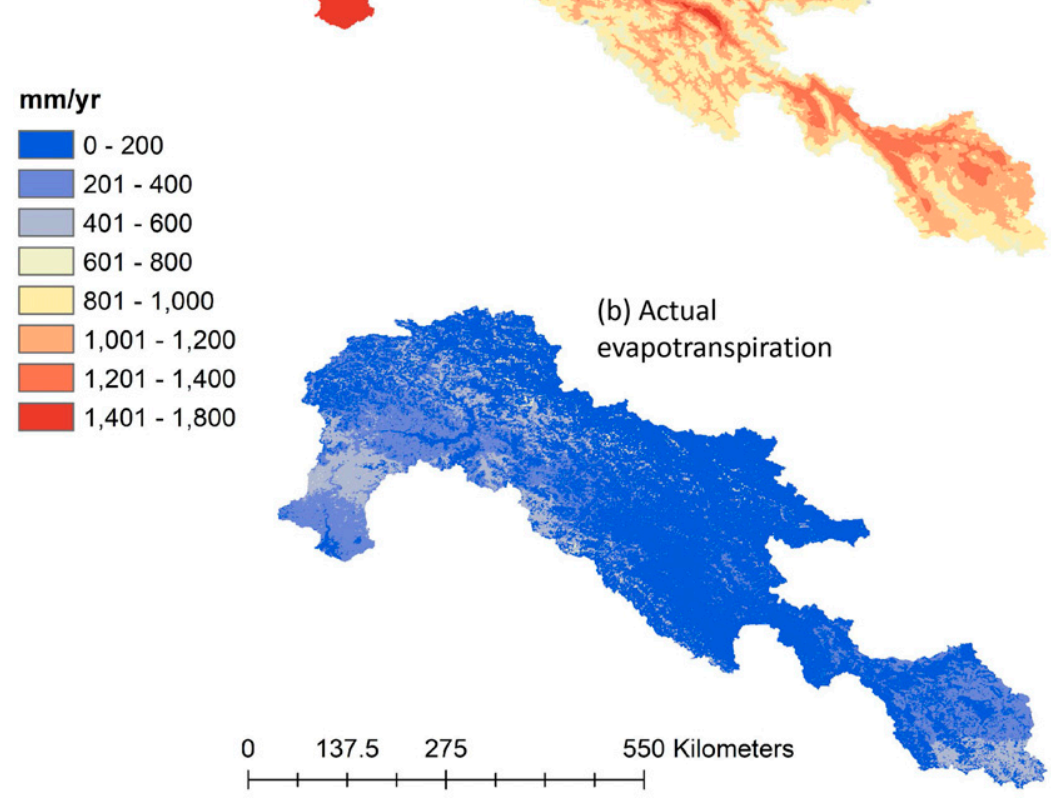

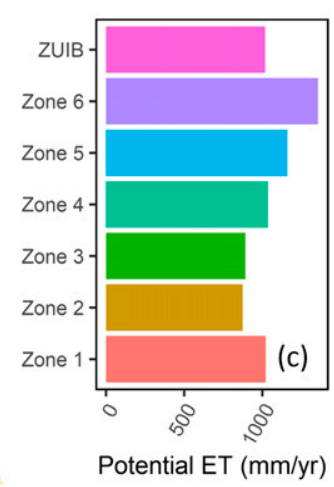

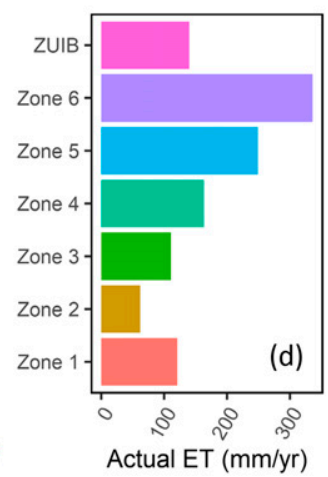

FIG. 2. Annual potential and actual evapotranspiration in UIB and mean values in different zones.

identify the more sensitive parameter and dominant driver to influence $P_{T}$ in each zone (see the supplemental material).

In the second step, TRMM precipitation was resampled at $1-\mathrm{km}^{2}$ resolution to construct a reference precipitation spatial field. The distribution of TRMM precipitation $\left[P_{\text {TRMM }}(Z)\right]$ was derived based on the elevation of grid stations using a digital elevation model (DEM) obtained from the U.S. Geological Survey (http://www.usgs.gov). After that, a spatial field of estimated initial precipitation lapse rate $\left(P_{\mathrm{LR}}\right.$; $\% \mathrm{~m}^{-1}$ ) was generated using $P_{\mathrm{TRMM}}(Z)$ grids. The $P_{\mathrm{LR}}$ values represent the elevation dependence of TRMM precipitation in each zone.

In the third step, a geospatial field of correction factor was generated in each zone to correct the TRMM precipitation along the horizontal and vertical profile. The function proposed by Wortmann et al. (2018) was used to generate the geospatial fields of the correction factor. The parameters used in this function were either collected from literature or derived from uncorrected data. The calibration or adjustment of these parameters was necessary to get reliable results. Therefore, two linear functions [Eqs. (2) and (3)] proposed by Immerzeel et al. (2012) were applied to calibrate the $P_{\mathrm{LR}}$, maximum precipitation altitude $Z_{\max }$, and reference elevation $Z_{\text {ref }}$ using TRMM precipitation by keeping the estimated $P_{T}$ constant in each zone. The initial values of $Z_{\text {max }}$ and $Z_{\text {ref }}$ were collected from literature (e.g., Barry 1992; Brun et al. 2017; Dahri et al. 2018; Hewitt 2005, 2007, 2011; Immerzeel et al. 2012, 2014, 2015; Putkonen 2004; Wake 1989; Winiger et al. 2005; Wortmann et al. 2018). The values of $P_{\mathrm{LR}}$ and $Z_{\max }$ were constrained based on observed mass balance and the above-cited literature. The values of $Z_{\max }$ were higher in the Karakorum and Hindu Kush regions than that in the western Himalayas. Based on the functions [Eqs. (2) and (3)], the precipitation was allowed to lapse positively between $Z_{\text {ref }}$ and $Z_{\max }$ by $P_{\mathrm{LR}}$. The precipitation negatively lapsed after approaching $Z_{\max }$ by the same magnitude of $P_{\mathrm{LR}}$. The linear functions are as follows:

$$
\text { for } \begin{aligned}
Z_{\text {ref }}<Z \leq Z_{\max }, \quad P_{T}= & P_{\mathrm{TRMM}} \times\left[1+\left(Z-Z_{\mathrm{ref}}\right)\right. \\
& \left.\times P_{\mathrm{LR}} \times 0.01\right],
\end{aligned}
$$

for $\quad Z>Z_{\text {max }}, \quad P_{T}=P_{\text {TRMM }} \times\left(1+\left\{\left[\left(Z_{\text {max }}-Z_{\text {ref }}\right)\right.\right.\right.$

$$
\left.\left.\left.+\left(Z_{\max }-Z\right)\right] \times P_{\mathrm{LR}} \times 0.01\right\}\right)
$$




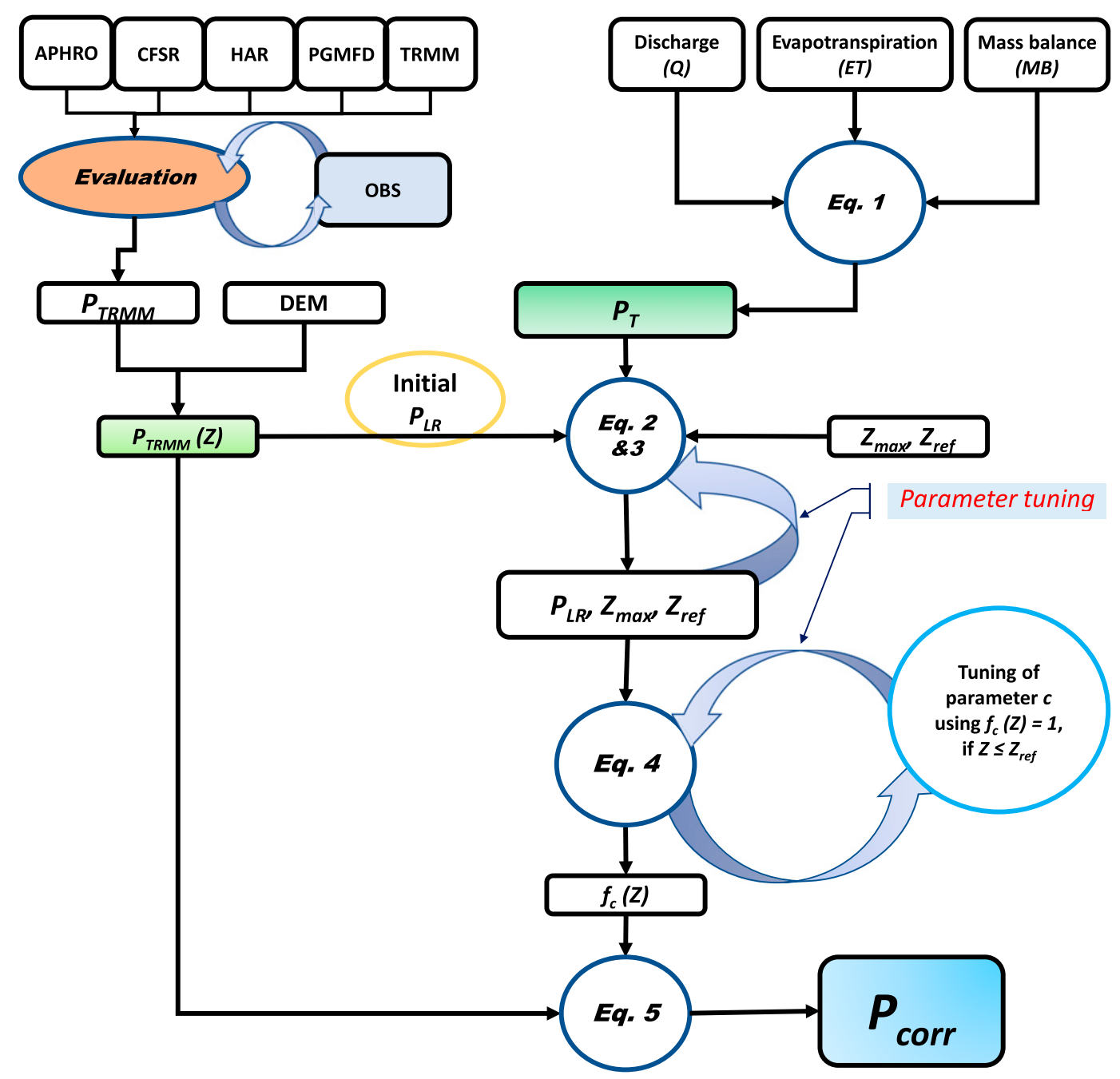

FIG. 3. Flowchart to describe the procedure of precipitation correction. The parameters are described in the text.

The calibrated values of $P_{\mathrm{LR}}$ and $Z_{\max }$ were applied to calculate the correction factor $f_{c}$ using Eq. (4) (Wortmann et al. 2018). The initial values of maximum correction $c$ were derived from the mass balance data and hydrometeorological studies (Brun et al. 2017; Dahri et al. 2016; Dahri et al. 2018; Gardelle et al. 2013; Immerzeel et al. 2012, 2015; Lutz et al. 2016; Wortmann et al. 2018). Then, the parameter $c$ was tuned up by keeping $f_{c}=1$ up to the $Z_{\text {ref }}$ and $P_{T}$ constant in each zone. The values of $f_{c}$ increased exponentially up to a maximum value of $P_{\mathrm{LR}}$. The maximum value of $c$ was applied at altitude $Z_{\max }$ and decreased after that at higher elevations:

$$
\begin{aligned}
f_{c}(Z)= & (c-1) \times \exp \left\{-\left[\frac{P_{\mathrm{LR}}}{(c-1) \times 100}\right]^{2}\right. \\
& \left.\times\left(Z-Z_{\max }\right)^{2}\right\}+1 .
\end{aligned}
$$

In the fourth step, the spatial fields generated by values of $f_{c}$ and TRMM precipitation were used to construct spatial fields of corrected precipitation $P_{\text {corr }}$ in each zone:

$$
P_{\text {corr }}=f_{c} \times P_{\text {TRMM }} \text {. }
$$

The parameter $Z_{\max }$ is the physical limit of moisture loss from the atmosphere and $c$ is the greatest correction applied. Finally, a sensitivity analysis was performed to reveal the sensitive variable(s) influencing the $P_{\text {corr }}$ (see supplemental material).

The simulated discharge was calculated based on the conceptual water balance using $P_{\text {corr }}, \mathrm{ET}_{a}$, and MB data. Then, it was compared with the observed discharge to evaluate whether $P_{\text {corr }}$ could reproduce and close the water balance in the UIB. The physical realism or correctness of $P_{\text {corr }}$ was compared with other datasets using a nondimensional hydrological 
graph (Andréassian and Perrin 2012; Coron et al. 2015; Valéry et al. 2010), an alternative to a well-known nondimensional Turc-Budyko plot (Budyko 1974; Turc 1954), based on the runoff coefficient $(Q / P)$ plotted against the aridity index $\left(P / \mathrm{ET}_{p}\right)$. Only, the physically realistic precipitation data can close a plausible water balance, and represent a true or realistic catchment (Andréassian and Perrin 2012).

The whole elevational profile of each zone was divided into different elevation bands $(100 \mathrm{~m}$ each) to explore the vertical distribution of precipitation based on all the datasets including $P_{\text {corr }}$. The altitudinal distribution of gridded and observed precipitation was compared against $P_{\text {corr }}$. All the datasets were resampled at $1-\mathrm{km}^{2}$ resolution for the comparison purpose; therefore, a sensitivity analysis was performed to identify the uncertainty, which might occur due to such rescaling (see supplemental material).

\section{Results}

The horizontal distribution and performance of five gridded precipitation gridded datasets were evaluated against the OBS precipitation for 2001-07 in UIB. An orographically corrected precipitation dataset was generated based on water and mass balance, and then, the vertical distribution of precipitation was revealed in UIB. The suitability of datasets was identified based on performance and their ability to reproduce the water balance in UIB.

\section{a. Comparison and performance evaluation}

The horizontal spatial distribution showed that mean annual OBS precipitation was higher over west Karakorum and Hindu Kush regions in the northern parts of UIB (Fig. 4a). Mean annual OBS precipitation was $340 \mathrm{~mm} \mathrm{yr}^{-1}$ over the entire UIB. However, mean annual precipitation varied widely between the observed and selected gridded precipitation datasets (Fig. 4a). The disagreements were apparent in mean annual values in UIB (Fig. 4b) and among different zones (Fig. 4c). Among all datasets, HAR and APHRO showed the highest and lowest mean annual precipitation in UIB (Fig. 4b). TRMM precipitation had a minimum percent bias $(3 \%-13 \%)$ with OBS in UIB. The highest percent bias was observed for HAR followed by CFSR, where mean annual precipitation was relatively overestimated by $80 \%$ and $67 \%$ comparative to OBS, respectively.

The distribution of precipitation was different for different datasets in six zones of UIB. OBS and CFSR had the highest mean annual precipitation in zone 5 and zone 4, respectively. APHRO, HAR, PGMFD, and
TRMM had the highest mean annual precipitation in zone 6 , where the average elevation was minimum among all the zones in UIB (Fig. 1). OBS, APHRO, CFSR, and HAR had minimum mean annual precipitation over west Himalayas, that is, zone 1. PGMFD and TRMM had the lowest mean annual precipitation in the west Karakorum and the east Karakorum, respectively (Fig. 4c). The spatial distribution patterns of OBS and all selected gridded precipitation datasets had higher resemblance in zone 6 and east fringe of zone 1, the zone 6 had the lowest average elevation while zone 1 was mostly influenced by monsoons. In the western parts of UIB, the spatial distribution patterns of HAR and CFSR had higher resemblance with OBS precipitation (Fig. 4a).

APHRO and TRMM imitated the bimodel hyetograph of OBS precipitation (Fig. 5a). The higher peak of OBS precipitation was appeared in April highlighting the dominance of westerlies in the region. The second peak occurred in August as a result of summer monsoons. The second peak of CFSR appeared in September which differed from the second peak of OBS precipitation in August. The second peak of PGMFD was not prominent enough; whereas, the two peaks of HAR precipitation occurred during February and April. Similarly, the seasonal distribution of precipitation showed that spring season contributed the largest part to annual precipitation among all seasons for all datasets (Fig. 5b). The combined contribution of winter and spring precipitation to annual precipitation was between $63 \%$ and $77 \%$ for all the datasets. The combination of winter and spring precipitation is usually termed as winter precipitation in UIB, and it occurs mostly in solid form due to westerlies. Among all the datasets, the percent bias of seasonal TRMM precipitation with OBS was the least (from $-4 \%$ to $+7 \%$ ). Moreover, the seasonal distribution pattern of TRMM was noted as almost similar to the OBS precipitation (Fig. 5b).

The performance of selected gridded precipitation datasets was presented using Taylor's diagram based on standard deviation, correlation coefficient, and rootmean-square error at monthly, seasonal, and annual scales (Figs. $5 \mathrm{c}-\mathrm{e}$ ). The proximity of gridded datasets to OBS indicated a good performance. The TRMM precipitation had the best performance at monthly, seasonal, and annual scales (CC $>0.9)$. HAR precipitation had the worst performance at all three scales. The standard deviations of APHRO and PGMFD were similar to that of the OBS precipitation at monthly scales.

The ability of precipitation datasets to represent the discharge variability was not satisfactory, as shown in the scatterplots between precipitation and discharge in UIB (Fig. 6a). The correlation and slope of OBS and 


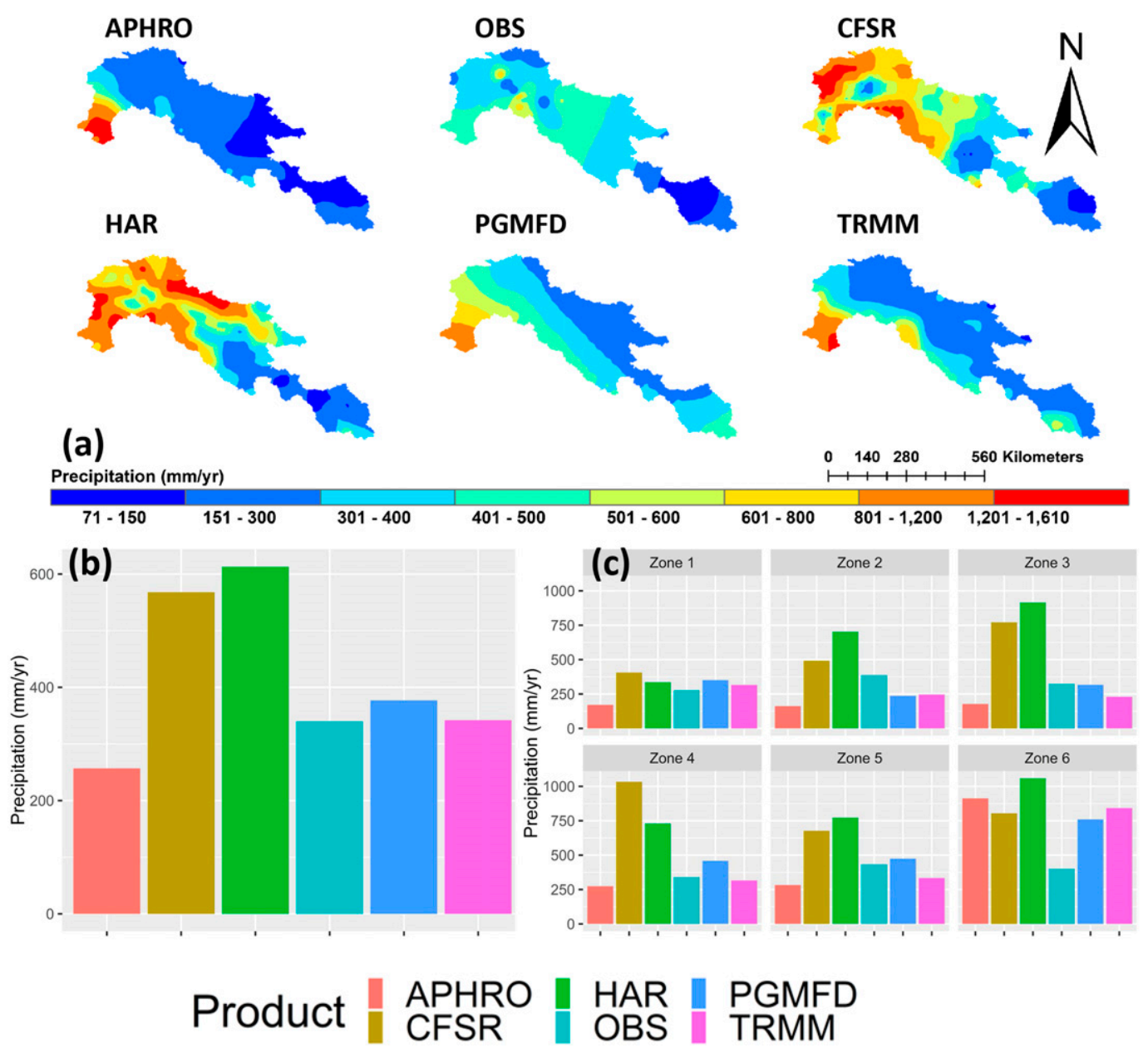

FIG. 4. (a) Spatial distribution of precipitation in UIB based on observed (OBS) and five selected gridded precipitation datasets. (b) Mean annual precipitation in UIB based on different datasets. (c) Mean annual precipitation in different zones of UIB.

TRMM precipitation with discharge were almost similar to each other. The runoff coefficient, the ratio of catchment discharge to precipitation $(Q / P)$, can indicate the first-order bias (under or overestimation) of precipitation datasets in a catchment. Runoff coefficients for OBS, APHRO, PGMFD, and TRMM were greater than $1(Q / P>1)$, which represented an underestimation of catchment precipitation in UIB (Fig. 6b). Again, the runoff coefficients for OBS and TRMM were almost similar, showing the similar type and magnitude of underestimation. The runoff coefficients for CFSR and HAR were less than $1(Q / P<1)$, indicating that these datasets can reproduce a plausible water balance in UIB.

The relationship between discharge and precipitation was not homogeneous in all zones of UIB (Fig. 6b). The runoff coefficients for all the datasets were less than one $(<1)$ in zone 1 and zone 6 except APHRO in zone 1 and
HAR in zone 6. The runoff coefficients for all the datasets were greater than $1(>1)$ in zone 5 . Overall, runoff coefficient ranges were $0.72-2.35,0.86-4.22,0.50-1.40$, 0.60-1.29, 0.57-2.61, and 0.64-3.52 for OBS, APHRO, CFSR, HAR, PGMFD, and TRMM datasets, respectively. Runoff coefficients roughly varied with glacier cover, elevation, and aridity in different parts of UIB.

The summary of performance evaluation and comparison of selected gridded datasets is as follows: (i) APHRO was underestimated, TRMM and PGMFD are slightly overestimated, HAR and CFSR were overestimated reasonably; (ii) APHRO and TRMM imitated the bimodal intra-annual hyetograph of OBS precipitation; (iii) the largest part of the annual precipitation was contributed during the winter and spring seasons for all the datasets, while TRMM performed the best among all the datasets; (iv) CSFR and HAR had runoff coefficients less than 1 and could reproduce a 
(a)
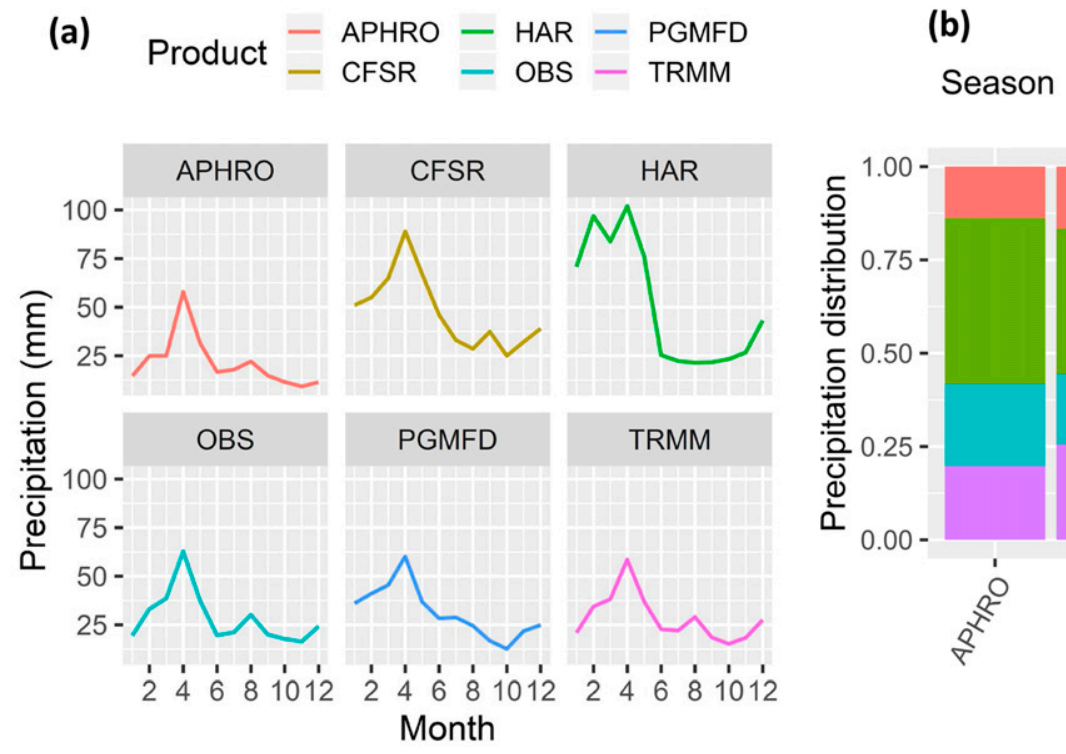

(b)

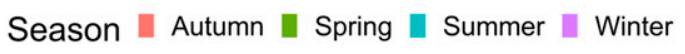
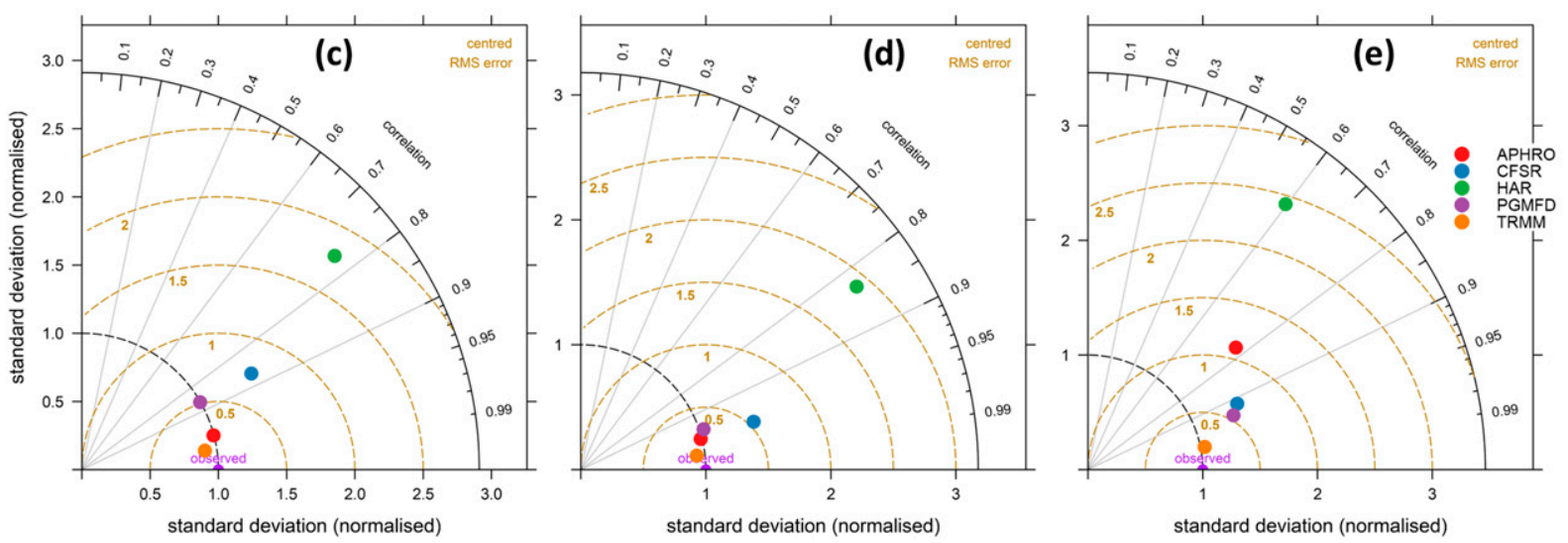

FIG. 5. (a) Temporal distribution of precipitation based on OBS and selected gridded precipitation datasets at monthly scale, (b) seasonal distribution of precipitation based on OBS and gridded datasets in UIB, and Taylor diagrams comparing gridded datasets with OBS at (c) monthly, (d) seasonal, and (e) annual scale for the period of 2001-07.

plausible hydrological balance in UIB. Overall, all the datasets had issues in representing the climatology and hydrology in UIB, that is, the amount of OBS, APHRO, PGMFD, and TRMM precipitation was insufficient to sustain the water and mass balance in the UIB (Fig. 6a) while the spatiotemporal distribution of CFSR and HAR was not consistent with OBS precipitation (Figs. 4 and 5).

Based on the sensitivity analysis, it was noted that downscaling reduced the magnitude of gridded precipitation substantially for all products in zone 6 (Fig. S4 in the online supplemental material). The upscaling of OBS precipitation had no discernible effects on the average precipitation in different zones of UIB.

\section{b. Corrected precipitation dataset}

The corrected precipitation dataset was generated to assess the exact amount of under or overestimation and to investigate the vertical precipitation distribution based on all the datasets in UIB. The average corrected precipitation ranged between 309 and $1036 \mathrm{~mm} \mathrm{yr}^{-1}$ among all the zones with an average of $593 \mathrm{~mm} \mathrm{yr}^{-1}$ in the whole UIB. The horizontal distribution of corrected precipitation is shown in Fig. 7a. The maximum and minimum corrected precipitation was estimated in zone 6 and zone 1 , respectively. Zone 6 , with the lowest average elevation, was influenced by both the westerlies and monsoon. Zone 1, in the Himalayas, was mostly influenced by the monsoon. However, the monsoon had a lower impact on mean annual precipitation because of its higher average elevation and being on the leeward side. Averagely, the maximum underestimation and overestimation for all the datasets were noted between -743 and $168 \mathrm{~mm} \mathrm{yr}^{-1}$ as compared to $P_{\text {corr }}$ over six zones in UIB, respectively. The average correction 

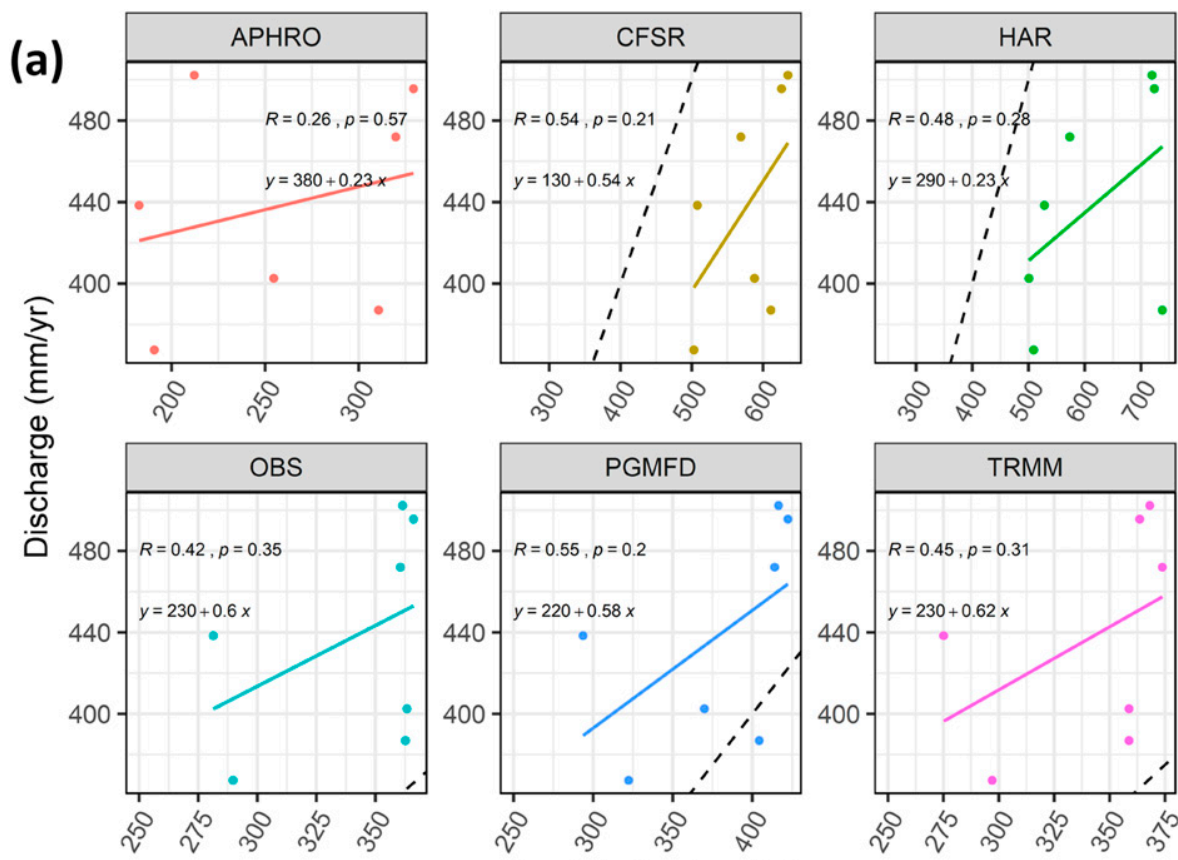

Product

$\rightarrow$ APHRO

- CFSR
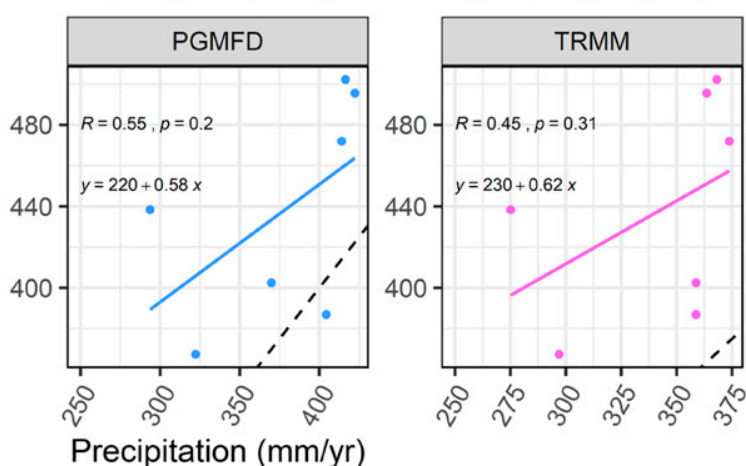

$\because$ HAR

- OBS

- PGMFD

$\rightarrow$ TRMM

(b)
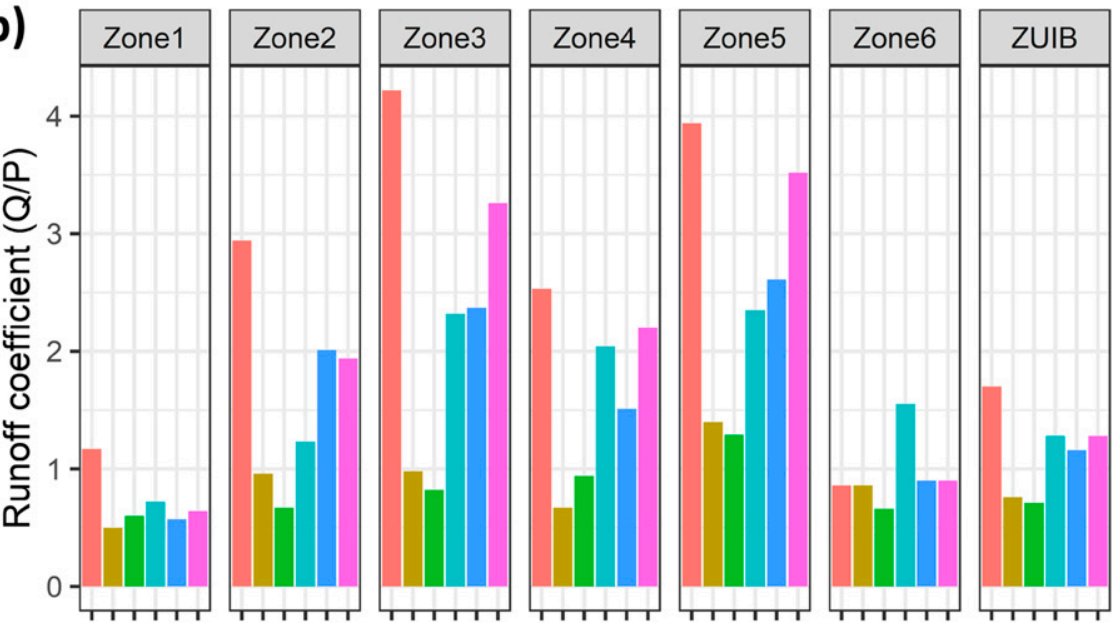

Product

APHRO

CFSR

HAR

OBS

PGMFD

TRMM

FIG. 6. (a) Relationship between precipitation and discharge in UIB based on observed (OBS) and five gridded precipitation datasets. (b) Runoff coefficients $(Q / P)$ in different zones and the entire UIB based on different precipitation datasets.

factor $f_{c}$, calculated using Eq. (4), ranged between 1 and 6 among the six zones with average maximum and minimum values in zone 3 and zone 6 , respectively (Fig. 7b). The glacier area ratio, elevation, and characteristics of precipitation sources were among the major factors affecting the magnitude of correction in the respective zone.

The spatial relations within the horizontal distribution of corrected precipitation were described by standard deviation values (Fig. 7c). The standard deviation was the highest in zone $4\left(433 \mathrm{~mm} \mathrm{yr}^{-1}\right)$ followed by zone 5 $\left(358 \mathrm{~mm} \mathrm{yr}^{-1}\right)$ and minimum in zone $1\left(88 \mathrm{~mm} \mathrm{yr}^{-1}\right)$. The spatial patterns of uncertainty were described by the coefficient of variation (Fig. 7d). The spatial uncertainty was maximum $(49 \%)$ in zone 4 over the Hindu Kush region and minimum $(28 \%)$ in zone 1 over the Himalayas. The elevation and glacier cover were the main factors affecting the spatial uncertainty of precipitation in UIB.

The ratio between the corrected precipitation and the other datasets (Fig. 8) represents the exact amount of under and overestimation of precipitation as compared 

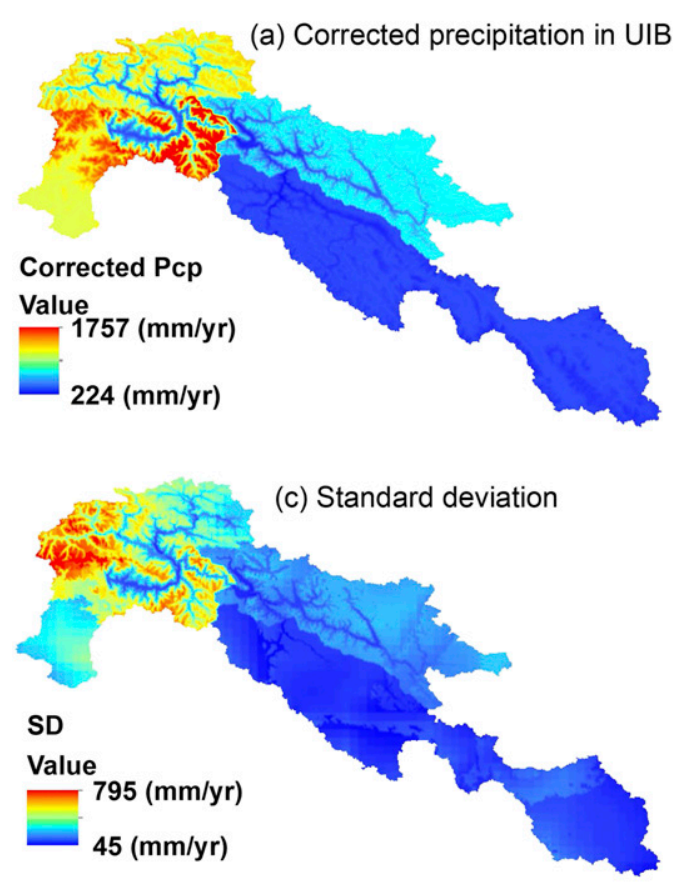

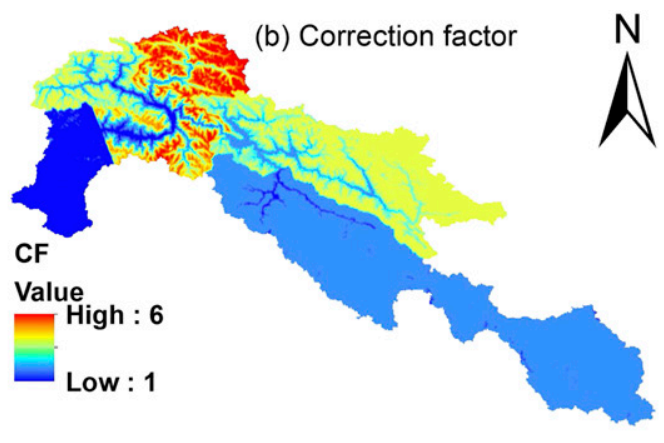

(d) Coefficient of variation

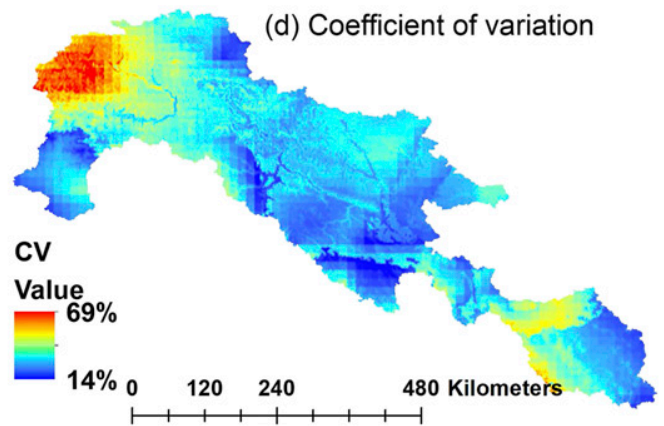

FIG. 7. Spatial distribution of (a) corrected precipitation, (b) correction factor, (c) standard deviation, and (d) coefficient of variation in UIB.

to the corrected precipitation dataset. The value ranges of the ratio between corrected precipitation and OBS, APHRO, CFSR, HAR, PGMFD, and TRMM were 0.47-6.99, 0.67-8.03, 0.23-6.16, 0.19-3.23, 0.46-5.03, and 0.35-7.22, respectively (Fig. 8). The average corrected precipitation was higher than OBS, APHRO, CFSR, HAR, PGMFD, and TRMM by a factor of 1.9, 2.9, 1.2,
1.1, 1.7, and 2.0 in the in UIB, respectively. The average ratio between corrected and other datasets was the highest in zone 3 for OBS, APHRO, PGMFD, and TRMM and in zone 5 for CFSR and HAR. The highest value of ratio indicated the largest underestimation while the values less than 1 indicate overestimation in gridded datasets as well as OBS (Fig. 8).
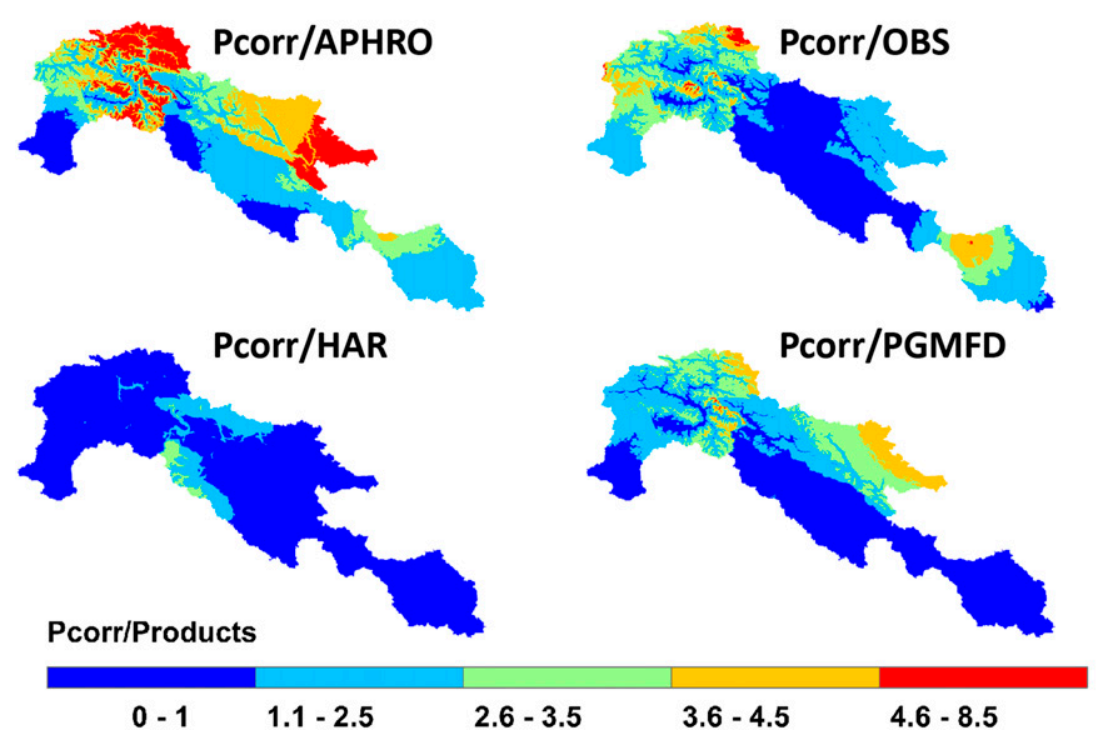
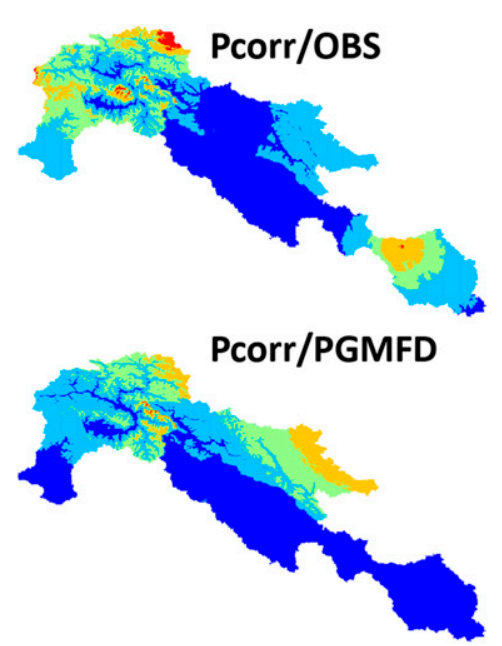
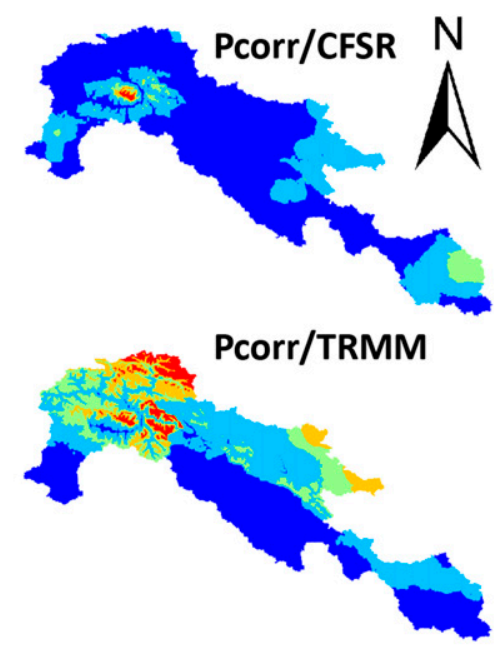

$0150300 \quad 600$ Kilometers

FIG. 8. Spatial distribution of ratio between corrected precipitation and other datasets in UIB. 

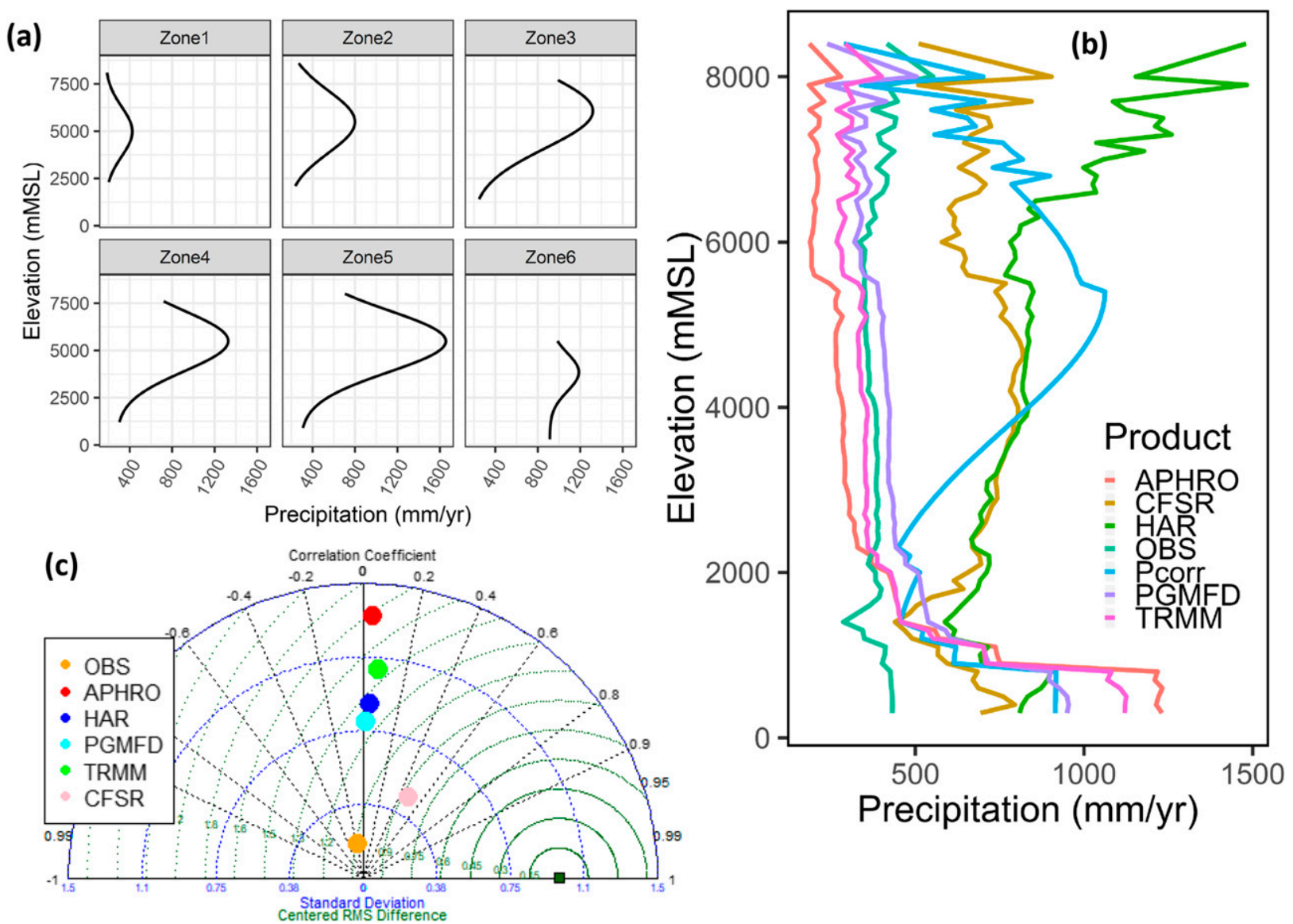

FIG. 9. Vertical distribution of precipitation in (a) different zones and (b) the entire UIB. (c) Taylor diagram for the visual representation of comparison results between corrected precipitation and other datasets along the vertical profile.

\section{c. Vertical distribution of precipitation}

Our results revealed that precipitation was strongly correlated to elevation. The precipitation increased by $0.123 \% \mathrm{~m}^{-1}$ along the vertical profile up to an elevation with maximum precipitation $\left(Z_{\max }\right)$. The $Z_{\max }$ was higher in the Karakorum and Hindu Kush region (zone 4) as compared to Himalayas (Fig. 9a) because these regions were influenced mostly by westerlies. The precipitation gradient was the highest $\left(0.235 \% \mathrm{~m}^{-1}\right)$ in zone 5 , where the Hindu Kush, Karakorum, and Himalayas intersect (Fig. 9a) and the lowest $\left(0.0273 \% \mathrm{~m}^{-1}\right)$ in zone 6 , where glacier area ratio was the lowest (i.e., $1.76 \%$; Table 1). The precipitation gradients along the elevation were corrected based on mass balance. Our inverse modeling results indicated that higher precipitation was required in accumulation areas to sustain large glacier systems in UIB. However, the gridded and OBS precipitation in those regions were underestimated by a factor of 3-8 (Fig. 8) as compared to corrected precipitation.

The highest mean annual $P_{\text {corr }}\left(1033 \mathrm{~mm} \mathrm{yr}^{-1}\right)$ was found in the elevation belt between 4700 and $5500 \mathrm{~m}$ compared to $354,268,780,837,401$, and $338 \mathrm{~mm} \mathrm{yr}^{-1}$ for OBS, APHRO, CFSR, HAR, PGMFD, and TRMM in the same elevation belt, respectively. The main waterproducing elevation zone was located between 3900 and $6600 \mathrm{~m}$ MSL elevation, where maximum average rain and snow precipitated annually (Fig. 9b). In contrast to corrected precipitation and other datasets, HAR had higher precipitation in higher elevation belt than that in lower elevations.

The results of the comparison between the vertical distribution of corrected precipitation and other datasets in UIB are shown in Fig. 9c. The correlations between the vertical distribution of corrected precipitation and other datasets were very low. Only CSFR distribution along the vertical profile had a reasonable correlation coefficient $(\mathrm{CC}>0.4)$, while the correlation between the vertical distribution of corrected and OBS precipitation was even negative. APHRO had the highest centered RMS difference followed by TRMM along the vertical profile in UIB highlighting the maximum underestimation in these datasets. CSFR had 

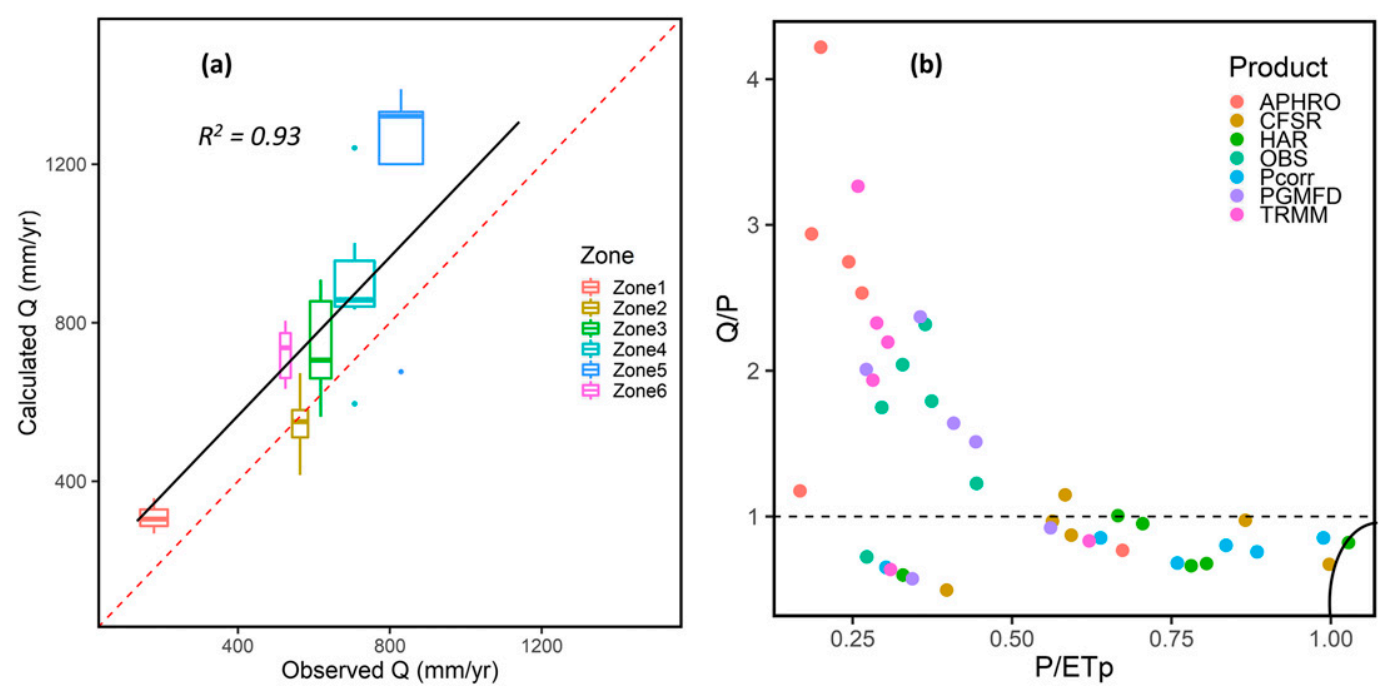

FIG. 10. (a) Validation of corrected precipitation using observed and calculated discharge. (b) Physical realism of corrected precipitation based on the nondimensional graphical representation of different zones in UIB using their discharge, precipitation, and potential evapotranspiration. The black line at the bottom-right of the graph represents the theoretical Budyko relationship in the nondimensional graph; $Q / P=$ runoff coefficient, and $P / \mathrm{ET} p=$ aridity index.

the lowest centered RMS difference with corrected precipitation highlighting overall lesser bias.

The sensitivity analysis highlighted that a certain amount of uncertainty could occur when gridded datasets and corrected precipitation were rescaled. The coarser grids $\left(\sim 25 \mathrm{~km}^{2}\right)$ at lower elevations had higher values, whereas finer grids at higher elevations tended to have higher values (Fig. S5). Such behavior indicated the role of elevation to affect the reliability of any datasets after rescaling.

\section{d. Validation and physical realism}

The validation of corrected precipitation was done independently by comparing calculated discharge against observed discharge in all zones of UIB. The calculated discharge was estimated using a conceptual hydrological balance model based on the $P_{\text {corr }}, \mathrm{ET}_{a}$, and MB data in each zone. A strong agreement $\left(R^{2}=0.93\right)$ was noticed between the calculated and observed annual discharge (Fig. 10a). The average calculated discharge was higher than the observed in all the zones except zone 2 .

The physical realism or correctness of the corrected precipitation results was confirmed using a hydrological alternative to Turc-Budyko plot (Fig. 10b). Most of the runoff coefficients for OBS and gridded precipitation datasets were greater than 1 in all the zones of UIB, indicating an unrealistic situation. The runoff coefficients values for corrected precipitation were much more plausible $(<1)$ in UIB. The CSFR and HAR had an aridity index more than $1\left(P / \mathrm{ET}_{p}>1\right)$ in zone 3 , and this situation is physically unrealistic. The aridity index for corrected precipitation was less than 1 in all zones meaning that the discharge was not smaller than the difference between $P$ and $\mathrm{ET}_{p}$. Zone 3 and zone 5 were wetter than other zones in UIB. The theoretical Budyko curve was different in UIB than that in nonglacierized catchments due to an additional water source from glacier melt. Overall, the results suggested that corrected precipitation was physically more realistic and can reproduce a plausible water balance in UIB.

\section{Discussions}

The efficiency of hydrological modeling appears highly sensitive to the choice of precipitation dataset. The actual representation of the precipitation is possible when topography is accounted because the altitude is the most constraining factor in precipitation datasets. Observed precipitation cannot represent the highaltitude precipitation, which is critical in glacierized catchments. However, an orographically corrected precipitation dataset may represent the actual distribution of precipitation in a catchment. The corrected precipitation dataset should be used as the reference for estimating the actual biases in the gridded precipitation datasets. In the current study, TRMM dataset out of five gridded precipitation datasets is selected based on performance evaluation against OBS, and then, corrected precipitation dataset is constructed based on water and 
mass balance in UIB. The vertical distribution of precipitation is revealed based on all the datasets in UIB.

\section{a. Spatiotemporal distribution and performance of gridded precipitation}

The precipitation in UIB occurs due to westerlies, monsoon, and intrabasin moisture recycling (Tuinenburg et al. 2012; Wei et al. 2013). Most of the observation meteorological stations are located at lower elevations and unevenly distributed in the UIB (Fig. 1), so there are substantial chances of uncertainties in observed precipitation distribution (Fig. 4a) in addition to undercatch errors, which are common in windy and snow-dominated areas (Rasmussen et al. 2012; Sieck et al. 2007). Reliable and accurate precipitation data are crucial for hydrological modeling and water resources management. The gridded datasets have been used across a wide range of hydrological modeling research around the world. For example, simulating the climate change impacts on future water availability (Lutz et al. 2016), simulating glaciohydrology (Wang et al. 2018), monitoring of floods and droughts (AghaKouchak et al. 2015), among the others. The representation of precipitation in gridded datasets is not consistent while these datasets have substantial differences with observed as well as among themselves (Figs. 4 and 5), and these differences are mostly due to the deficiencies in their data sources and generation mechanisms (Sun et al. 2018).

The TRMM precipitation dataset is identified as the best dataset with higher correlation and lesser bias with the OBS data. Our results suggest that APHRO precipitation is substantially underestimated (Figs. 4 and 5) and cannot be applied in hydrological modeling studies without correction. Similar findings are presented by Dahri et al. (2016) in UIB, even though their study area is bigger as compared to the current study. The meteorological stations used to produce APHRO dataset (Yatagai et al. 2012) are probably located at lower elevations and cannot represent the high-altitude precipitation. Lutz et al. (2016) applied APHRO precipitation in their hydrological modeling in UIB, but they used correction factors based on mass balance proposed by Immerzeel et al. (2015) to correct precipitation before its application. As APHRO and TRMM both represent the monthly and seasonal precipitation cycle very well and imitate the observed bimodal hyetograph (Fig. 5a); therefore, these datasets have more potential to represent the precipitation at temporal scales. The performance of APHRO precipitation has been found inferior to TRMM when compared with OBS (Fig. 5) especially at annual scale (Fig. 5e). Thus, TRMM has been identified as a better choice because of its lesser bias, higher correlation, and better temporal representation in UIB.
Several studies have reported a very low amount of annual precipitation in UIB quantified from different products [e.g., $300 \mathrm{~mm}$ based on TRMM in Bookhagen and Burbank (2010) and Immerzeel et al. (2009, 2010)]. Many previous studies have discussed the applicability, usefulness, calibration, and limitations of TRMM dataset in Himalaya-Karakorum-Hindu Kush region (Ali et al. 2017; Anjum et al. 2016, 2018; Bookhagen and Burbank 2006, 2010; Cheema and Bastiaanssen 2012; Dahri et al. 2016; Khan et al. 2018; Khan et al. 2014; Maggioni et al. 2016). The differences in our and their results owing to different coverage of study area, periods, and meteorological stations applied in the analysis. The CFSR and HAR datasets have been found highly overestimated as compared to the observed precipitation in our results (Figs. 4 and 5).

\section{b. Insufficiency to sustain the mass and water balance}

The runoff coefficients are the first-order indication of precipitation under or overestimation to close the water balance in a catchment. Most of the available precipitation datasets including OBS are not able to close the water balance in UIB because the runoff coefficients $(Q / P)$ have been estimated as greater than 1 (Fig. 6b). The mountain regions generally exhibit higher runoff coefficients because of faster surface runoff due to the existence of shallow soils, steeper slopes, glaciers, and permafrost (Goel 2011). Previous studies in UIB and neighboring glacierized catchments (Immerzeel et al. 2015; Wortmann et al. 2018) have suggested that runoff coefficients are higher than 1 for gridded precipitation datasets, including APHRO dataset. Under reasonable mass balance assumptions, the negative mass balances in glacierized catchments can raise the runoff coefficients and vice versa. The runoff in glacierized catchments can be altered without any change in precipitation because it is usually contributed by glacier melt, which is dependent on temperature change (Luo et al. 2013). The evapotranspiration also remained lower because of low temperatures and sparse vegetation in these areas (Goel 2011). The coefficients greater than 1 are improbable and would signal a significant alteration of glaciers and catchment hydrology.

It is also argued that the observed gap between runoff (when $Q>P$ ) and precipitation (Fig. 6a) cannot be attributed to only the glacier mass changes (Kääb et al. 2012), and instead it is due to the underestimated precipitation mostly (Immerzeel et al. 2015); this is true for UIB (Fig. 10b). The water balance can be closed if the precipitation in gridded datasets is $2-8$ times greater than the original precipitation in these datasets at higher altitudes (Fig. 8). Similar conclusions have been drawn by Immerzeel et al. (2015) in UIB and Wortmann et al. (2018) 
in the Tarim River basin. The values are slightly different from their results owing to the use of different precipitation datasets, different size and location of study areas, and different mass balance values. The discharge exceeds the precipitation for most of the datasets in most of the zones as well as in the entire UIB (Fig. 6a) because highaltitude precipitation is underestimated in those datasets. Immerzeel et al. (2009) also conclude that gridded precipitation is not able to close the water balance at Tarbela, where annual average discharge exceeds the precipitation because of negative mass imbalance and underestimated high-altitude precipitation. Several geodetic mass balance studies (Brun et al. 2017; Gardelle et al. 2013; Kääb et al. 2015) have confirmed that glacier mass balance in most parts of UIB is not significantly negative and even experiencing mass gain in several parts. This confirms our conclusions that ice loss is not only the explanation for missing water in UIB.

\section{c. Actual precipitation is higher than most of the available datasets}

The precipitation is corrected using vertical precipitation gradients based on mass balance by inversely closing the natural water balance using true precipitation (Fig. 7) in UIB. The water balance has been reproduced using actual evapotranspiration, mass balance, and observed discharge based on a conceptual hydrological balance model [Eq. (1)]. Previous studies in Sweden, France, UIB, and the headwaters of Tarim River have generated corrected precipitation based on vertical precipitation gradients using observed mass balance and runoff in a physically realistic manner (Immerzeel et al. 2015; Khan and Koch 2018; Valéry et al. 2010; Wortmann et al. 2018). The mean annual corrected precipitation $\left(593 \mathrm{~mm} \mathrm{yr}^{-1}\right)$ in our study (Fig. 7a) is closer to the results of Reggiani and Rientjes (2015) and Immerzeel et al. (2015), who have suggested corrected precipitation as $675 \pm 100$ and $913 \pm 323 \mathrm{~mm} \mathrm{yr}^{-1}$, respectively. The different size of study areas, different approaches for actual evapotranspiration, and different mass balance assumptions are among the main reasons for differences in absolute values. This highlights that enough moisture is being transported by westerlies and monsoon in the region to account for our corrected precipitation. The results of this study highlight that higher precipitation is required to sustain water and mass balance in UIB. Hewitt (2007) and Immerzeel et al. (2015) have suggested similar conclusions for UIB.

The mean annual CFSR precipitation is $568 \mathrm{~mm} \mathrm{yr}^{-1}$, which is very close to our mean corrected precipitation $593 \mathrm{~mm} \mathrm{yr}^{-1}$ over the whole UIB (Figs. 4a and 7a). Averaged over whole UIB, CFSR has lesser spatial biases with corrected precipitation (Figs. 8 and 9a); therefore, it can be applied for reproducing water balance. However, there may be larger biases at smaller spatial and temporal scales. As, the temporal distribution of CFSR precipitation is not consistent with the OBS (Fig. 5); wherefore, it might hamper the temporal distribution of water balance components in UIB. Hence, it is recommended to correct a dataset that is more consistent with the temporal distribution of observed precipitation for hydrological applications.

\section{d. Higher precipitation at higher altitudes would produce higher runoff}

Uncertainties are generally higher at higher altitudes as compared to low-altitude zones in UIB (Fig. 7). The high glacierized catchments have higher correction factors and lower uncertainties than other high-altitude parts of the UIB. Similar findings have been presented by Wortmann et al. (2018) in glacierized catchments of Karakorum and Tien Shan mountains. Our results highlight that a higher amount of precipitation is required at higher altitudes, especially in the accumulation zones to sustain the glacier systems. Hewitt (2007) also suggests that around $2000 \mathrm{~mm} \mathrm{yr}^{-1}$ snowfall in accumulation areas is required to sustain larger glacier systems at high altitudes. While the gridded precipitation has been reported between 257 and $613 \mathrm{~mm} \mathrm{yr}^{-1}$ in UIB. The values of CFSR and HAR precipitation in vertical distribution are higher than the other datasets and closer to the corrected precipitation (Fig. 9b); however, the temporal performance of these products to represent the OBS precipitation is found unacceptable (Fig. 5). The corrected precipitation matches well with previous work on high-altitude precipitation in UIB and surrounding catchments (Dahri et al. 2018; Hewitt 2007; Immerzeel et al. 2015; Khan and Koch 2018; Winiger et al. 2005; Wortmann et al. 2018). Above $4000 \mathrm{~m}$ MSL, the accumulation values have been reported between 1000 and $3000 \mathrm{~mm}$ in the Karakorum region (Batura Glacier Investigation Group 1979; Wake 1989; Winiger et al. 2005). The highest amounts of precipitation have been reported at the junction of the Himalayan, Karakorum, and Hindu Kush mountain ranges, and this is also confirmed in the current study (Fig. 7).

Along the vertical profile, the highest mean annual corrected precipitation $\left(P>1000 \mathrm{~mm} \mathrm{yr}^{-1}\right)$ is distributed between 4700 and $5500 \mathrm{~m}$, whereas the precipitation in other datasets is underestimated in the same belt (Fig. 9b). The elevation zone between 3900 and $6600 \mathrm{~m}$ is identified as the main water-producing zone along the vertical profile (Fig. 9b). Immerzeel et al. (2015) have identified the greatest corrected precipitation totals between 3750 and $4250 \mathrm{~m}$ and main water-producing zone between 4250 and $4750 \mathrm{~m}$ along the vertical profile 
in UIB. The differences in findings owing mainly to different study area size and different mass balance values in their study. Considerable amounts of precipitation at higher altitudes (Figs. 7 and 9) are due to the westerly precipitation systems in the northwest part of UIB (Dahri et al. 2016). The westerlies have higher tropospheric altitude and stronger interplay with altitude (Immerzeel et al. 2015); wherefore, $Z_{\max }$ has been noticed higher in the Karakorum and Hindu Kush regions, which are mostly influenced by westerlies.

\section{e. Authenticity and uncertainties}

The sensitivity analysis of Eq. (1) shows that discharge is the dominant influencer to affect the true precipitation at catchment scale when the vertical distribution is not considered (see supplemental material). The correction function proposed by Wortmann et al. (2018) for possible orographic correction of precipitation in glacierized catchments has been proved valid to be applied in UIB. The function is used in combination with two linear functions proposed by Immerzeel et al. (2012) to calibrate and constrain the parameters, for example, precipitation gradients, maximum precipitation elevation, and maximum correction. The uncertainty in corrected precipitation caused by equifinality was reduced using both functions while constraining the parameters. However, the possible uncertainty in corrected precipitation [Eqs. (2)-(4)] might be due to the glacier hypsometry and mass balance data along the vertical profile. The mass balance has stronger control over the corrected precipitation because it constrains the precipitation gradients. The sensitivity analysis (see supplemental material) confirms that the distribution of glaciers along the elevation has a critical relationship with the parameters in Eqs. (2)-(4) to influence the amount and distribution of corrected precipitation in UIB. The parameters $P_{\mathrm{LR}}, Z_{\mathrm{max}}, Z_{\mathrm{ref}}$, and $c$ are directly or indirectly dependent on the distribution of mass balance along the vertical profile of glacierized catchments. The glacier distribution and mass balance variations are larger among the different zones in three mountain ranges (Fig. 1 and Table 1). Therefore, precipitation estimates can be improved by improving the mass balance estimates in UIB. Similar remarks have been provided in the previous studies in UIB and adjacent basins (Immerzeel et al. 2012, 2015; Lutz et al. 2016; Wortmann et al. 2018).

As the discharge is the most sensitive variable to have larger impact on precipitation (Fig. S1); therefore, validation of corrected precipitation based on the discharge highlight its applicability. A strong agreement between the observed and calculated discharge during the independent validation of corrected precipitation has proved its reliability (Fig. 10a). The observed discharge is lower than the simulated discharge in most of the cases. The results are in good match with the previous studies in the region (Immerzeel et al. 2015; Wortmann et al. 2018). The groundwater can play an important role in overall hydrology, but it is not considered in water balance analysis in this study and assumed that there is no net gain or loss in groundwater storage over the observed period 2001-07 in UIB. The groundwater may be stored temporarily in aquifers and pose a natural delay in runoff (Alley et al. 2002; Andermann et al. 2012). It is considered that there is no significant gain or loss over multiple years in UIB. However, for shorter periods like monthly and seasonal scales, the assumption may not be valid. Redistribution and sublimation may also play a significant role in glacierized high-altitude water balance (Wagnon et al. 2013), but these components are not accounted for in the conceptual water balance. The precipitation gradients are corrected based on the mass balances. Thus, it is assumed that the net corrected precipitation accounted for sublimation and redistributions.

The physical realism or correctness of corrected precipitation is confirmed using a hydrological alternative of Turc-Budyko plot (Fig. 10b). The points above the $Q / P=1$ line or moisture limit are physically unrealistic. Most of the precipitation datasets have their runoff coefficients greater than one. However, the runoff coefficients are less than 1 for corrected precipitation (Fig. 10b), which makes the water balance more realistic in all the zones of UIB. The aridity index values for CFSR and HAR in zone 3 are greater than 1, and they cross the energy limit of theoretical Budyko line (Fig. 10b), which means that runoff is smaller than the difference between the precipitation and potential evapotranspiration, making these catchments "leaky" (Andréassian and Perrin 2012). There are two significant possibilities for leaky catchments: water is flowing out of the catchment without being measured at the discharge gauge (measuring error) and overestimated precipitation. In UIB, the latter possibility is identified as dominant, assuming that observed discharge is accurate. In glacierized catchments, theoretical Budyko curve is different because of additional water from glacier imbalance due to which some of the discharge observations may not be aligned with the other water balance terms.

It is also important to mention that the results are sensitive to spatial resolution of the datasets. Any upscaling or downscaling may affect the amount of precipitation in any zone arbitrarily (see supplemental material). The sensitivity related to rescaling of precipitation may affect the results quantitatively; therefore, it is suggested to pay attention to the spatial resolution of datasets while interpreting the results. 


\section{Conclusions}

The main objective of the current study is to systematically evaluate the performance of five gridded datasets and reveal the vertical distribution of precipitation based on multiple precipitation datasets considering the suitability of precipitation datasets for hydrological applications in UIB. The datasets have been evaluated for an overlapped period 2001-07 at monthly, seasonal, and annual scales. Based on the results, it is concluded that the TRMM dataset has performed the best to represent the distribution of OBS precipitation with the lowest bias and highest correlation at different spatial and temporal scales.

Most of the precipitation datasets have been identified to underestimate when compared with observed runoff in UIB. The runoff coefficients for OBS, APHRO, PGMFD, and TRMM are greater than 1, and this makes them unrealistic to close the water balance in UIB. The observed gap between the runoff and precipitation is attributed to the underestimated precipitation but cannot be attributed to the glacier mass imbalance because glaciers mostly have been advancing or neutral in the region.

The vertical distribution of precipitation has revealed that corrected precipitation increases up to a certain altitude and then decreases based on the local water and mass balance in different zones. The corrected precipitation is different from other datasets and has produced a more plausible water balance in UIB. The CFSR precipitation is identified as the better dataset as compared to other datasets based on its vertical distribution; however, inconsistency with observed precipitation in temporal distribution limits its application in hydrological studies. The main water-producing elevation zone is located between 3900 and $6600 \mathrm{~m}$ MSL along the vertical profile in UIB.

The findings of the study improve the understanding of actual and gridded precipitation along the horizontal and vertical profile and may have significant effects on studies on modeling, planning, management, and designing of water resources under climate change. It is concluded with strong pieces of evidence that the precipitation in OBS and most of the gridded datasets is underestimated, especially at high altitudes; moreover, it is insufficient to sustain the water and mass balance in UIB.

The precipitation, especially its vertical distribution is the key to understand the glaciohydrology in the UIB. In UIB, the spatial distribution and magnitude of actual precipitation are very different from the observed and gridded precipitation datasets, which are being used in the planning and designing processes of reservoirs for irrigation systems and hydropower projects. The highaltitude precipitation usually falls in solid form and is stored in glaciers, but under consistent climate change in the future when the hydrologic regime in UIB will become more rain dominated, the importance and implications of these findings will become more apparent. Therefore, it is recommended that the gridded precipitation datasets should be corrected based on mass and water balance before their hydrological applications in glacierized catchments.

Acknowledgments. The research project was funded by National Natural Science Foundation China (NSFC Grant 41761144075) and the Strategic Priority Research Program of Chinese Academy of Sciences (Grant XDA20060301). The authors are grateful to the Water and Power Development Authority (WAPDA), Pakistan Meteorological Department (PMD), and China Meteorological Data Sharing Network (http://data.cma.cn/) for providing observed meteorological and hydrological data in the upper Indus basin. The first author is very thankful to CAS-TWAS President's Fellowship Program (https://twas.org/opportunity/cas-twas-presidentsphdfellowship-programme) for providing financial support for his Ph.D.

\section{REFERENCES}

AghaKouchak, A., A. Farahmand, F. S. Melton, J. Teixeira, M. C. Anderson, B. D. Wardlow, and C. R. Hain, 2015: Remote sensing of drought: Progress, challenges and opportunities. Rev. Geophys., 53, 452-480, https://doi.org/10.1002/2014RG000456.

Ahmad, Z., M. Hafeez, and I. Ahmad, 2012: Hydrology of mountainous areas in the upper Indus Basin, Northern Pakistan with the perspective of climate change. Environ. Monit. Assess. 184, 5255-5274, https://doi.org/10.1007/s10661-011-2337-7.

Ali, A., and Coauthors, 2017: Evaluation and comparison of TRMM multi-satellite precipitation products with reference to rain gauge observations in Hunza River basin, Karakoram Range, northern Pakistan. Sustainability, 9, 1954-1972, https:// doi.org/10.3390/su9111954.

Alley, W. M., R. W. Healy, J. W. LaBaugh, and T. E. Reilly, 2002: Flow and storage in groundwater systems. Science, 296, 1985-1990, https://doi.org/10.1126/science.1067123.

Andermann, C., L. Longuevergne, S. Bonnet, A. Crave, P. Davy, and R. Gloaguen, 2012: Impact of transient groundwater storage on the discharge of Himalayan rivers. Nat. Geosci., 5 , 127-132, https://doi.org/10.1038/ngeo1356.

Anders, A. M., G. H. Roe, B. Hallet, D. R. Montgomery, N. J. Finnegan, and J. Putkonen, 2006: Spatial patterns of precipitation and topography in the Himalaya. Tectonics, Climate, and Landscape Evolution, S. D. Willett et al., Eds., GSA Special Paper, Vol. 398, Geological Society of America, 39-53, https://doi.org/10.1130/2006.2398(03).

Andréassian, V., and C. Perrin, 2012: On the ambiguous interpretation of the Turc-Budyko nondimensional graph. Water Resour. Res., 48, W10601, https://doi.org/10.1029/ 2012WR012532. 
Anjum, M. N., Y. Ding, D. Shangguan, M. W. Ijaz, and S. Zhang, 2016: Evaluation of high-resolution satellite-based real-time and post-real-time precipitation estimates during $2010 \mathrm{ex}$ treme flood event in Swat River basin, Hindukush region. Adv. Meteor., 2016, 1-8, https://doi.org/10.1155/2016/2604980. - and Coauthors, 2018: Performance evaluation of latest Integrated Multi-Satellite Retrievals for Global Precipitation Measurement (IMERG) over the northern highlands of Pakistan. Atmos. Res., 205, 134-146, https://doi.org/10.1016/ j.atmosres.2018.02.010.

Antonio, T., and R. J. Zomer, 2018: Global Aridity Index and Potential Evapo-Transpiration (ET0) Climate Database v2. CGIAR Consortium for Spatial Information (CGIAR-CSI), https://cgiarcsi.community.

Bajracharya, S. R., and B. Shrestha, 2011: The status of glaciers in the Hindu Kush-Himalayan Region. International Centre for Integrated Mountain Development, 127 pp.

Barros, A. P., G. Kim, E. Williams, and S. W. Nesbitt, 2004 Probing orographic controls in the Himalayas during the monsoon using satellite imagery. Nat. Hazards Earth Syst. Sci., 4, 29-51, https://doi.org/10.5194/nhess-4-29-2004.

Barry, R. G., 1992: Mountain Weather and Climate. 3rd ed. Cambridge University Press, $500 \mathrm{pp}$

Batura Glacier Investigation Group, 1979: The Batura glacier in the Karakoram mountains and its variations. Sci. Sin., 22 958-974.

Bhatt, B. C., and K. Nakamura, 2005: Characteristics of monsoon rainfall around the Himalayas revealed by TRMM Precipitation Radar. Mon. Wea. Rev., 133, 149-165, https://doi.org/ 10.1175/MWR-2846.1.

Blacutt, L. A., D. L. Herdies, L. G. G. de Gonçalves, D. A. Vila, and M. Andrade, 2015: Precipitation comparison for the CFSR, MERRA, TRMM3B42 and combined scheme datasets in Bolivia. Atmos. Res., 163, 117-131, https://doi.org/10.1016/ j.atmosres.2015.02.002.

Bookhagen, B., and D. W. Burbank, 2006: Topography, relief, and TRMM-derived rainfall variations along the Himalaya. Geophys. Res. Lett., 33, L08405, https://doi.org/10.1029/ 2006 GL026037.

_ and - 2010: Toward a complete Himalayan hydrological budget: Spatiotemporal distribution of snowmelt and rainfall and their impact on river discharge. J. Geophys. Res. Earth, 115, F03019, https://doi.org/10.1029/2009JF001426.

Brun, F., E. Berthier, P. Wagnon, A. Kääb, and D. Treichler, 2017: A spatially resolved estimate of High Mountain Asia glacier mass balances from 2000 to 2016. Nat. Geosci., 10, 668-673, https://doi.org/10.1038/ngeo2999.

Budyko, M. I., 1974: Climate and Life. D. H. Miller, Ed., International Geophysics Series, Vol. 18, Academic Press, $508 \mathrm{pp}$.

Cheema, M. J. M., and W. G. M. Bastiaanssen, 2012: Local calibration of remotely sensed rainfall from the TRMM satellite for different periods and spatial scales in the Indus Basin. Int. J. Remote Sens., 33, 2603-2627, https://doi.org/10.1080/ 01431161.2011.617397.

Coron, L., V. Andréassian, C. Perrin, and N. Le Moine, 2015: Graphical tools based on Turc-Budyko plots to detect changes in catchment behaviour. Hydrol. Sci. J., 60, 1394-1407, https:// doi.org/10.1080/02626667.2014.964245.

Dahri, Z. H., F. Ludwig, E. Moors, B. Ahmad, A. Khan, and P. Kabat, 2016: An appraisal of precipitation distribution in the high-altitude catchments of the Indus basin. Sci. Total Environ., 548-549, 289-306, https://doi.org/10.1016/ j.scitotenv.2016.01.001.
E. Moors, F. Ludwig, S. Ahmad, A. Khan, I. Ali, and P. Kabat, 2018: Adjustment of measurement errors to reconcile precipitation distribution in the high-altitude Indus basin. Int. J. Climatol., 38, 3842-3860, https://doi.org/10.1002/joc.5539.

Dee, D. P., and Coauthors, 2011: The ERA-Interim reanalysis: Configuration and performance of the data assimilation system. Quart. J. Roy. Meteor. Soc., 137, 553-597, https://doi.org/ 10.1002/qj.828.

De Souza, K., E. Kituyi, B. Harvey, M. Leone, K. S. Murali, and J. D. Ford, 2015: Vulnerability to climate change in three hot spots in Africa and Asia: Key issues for policy-relevant adaptation and resilience-building research. Reg. Environ. Change, 15, 747-753, https://doi.org/10.1007/s10113-015-0755-8.

Dinku, T., S. J. Connor, P. Ceccato, and C. F. Ropelewski, 2008: Comparison of global gridded precipitation products over a mountainous region of Africa. Int. J. Climatol., 28, 1627-1638, https://doi.org/10.1002/joc.1669.

ESRI, 2019: Average annual actual evapotranspiration in mm/year. ArcGIS, https://www.arcgis.com/home/item.html? $\mathrm{id}=31 \mathrm{f} 7 \mathrm{c} 3727 \mathrm{abf} 42249 \mathrm{a} 43 \mathrm{fe} 8 \mathrm{f} 25470 \mathrm{af} 4$.

Filippi, L., E. Palazzi, J. von Hardenberg, and A. Provenzale, 2014: Multidecadal variations in the relationship between the NAO and winter precipitation in the Hindu KushKarakoram. J. Climate, 27, 7890-7902, https://doi.org/10.1175/ JCLI-D-14-00286.1.

Gampe, D., and R. Ludwig, 2017: Evaluation of gridded precipitation data products for hydrological applications in complex topography. Hydrology, 4, 53-53, https://doi.org/10.3390/ hydrology4040053.

Gao, Y. C., and M. F. Liu, 2013: Evaluation of high-resolution satellite precipitation products using rain gauge observations over the Tibetan Plateau. Hydrol. Earth Syst. Sci., 17, 837-849, https://doi.org/10.5194/hess-17-837-2013.

Gardelle, J., E. Berthier, Y. Arnaud, and A. Kääb, 2013: Regionwide glacier mass balances over the Pamir-KarakoramHimalaya during 1999-2011. Cryosphere, 7, 1263-1286, https:// doi.org/10.5194/tc-7-1263-2013.

Goel, M. K., 2011: Runoff coefficient. Encyclopedia of Snow, Ice and Glaciers, V. P. Singh, P. Singh, and U. K. Haritashya, Eds., Springer, 952-953.

Harris, I., P. D. Jones, T. J. Osborn, and D. H. Lister, 2014: Updated high-resolution grids of monthly climatic observations-The CRU TS3.10 dataset. Int. J. Climatol., 34, 623-642, https://doi.org/10.1002/joc.3711.

Hasson, S., V. Lucarini, M. R. Khan, M. Petitta, T. Bolch, and G. Gioli, 2014: Early 21st century snow cover state over the western river basins of the Indus River system. Hydrol. Earth Syst. Sci., 18, 4077-4100, https://doi.org/10.5194/ hess-18-4077-2014.

, J. Böhner, and V. Lucarini, 2017: Prevailing climatic trends and runoff response from Hindukush-Karakoram-Himalaya, upper Indus Basin. Earth System Dynamics, 8, 337-355, https://doi.org/10.5194/esd-8-337-2017.

Henn, B., A. J. Newman, B. Livneh, C. Daly, and J. D. Lundquist, 2018: An assessment of differences in gridded precipitation datasets in complex terrain. J. Hydrol., 556, 1205-1219, https:// doi.org/10.1016/j.jhydrol.2017.03.008.

Hewitt, K., 2005: The Karakoram anomaly? Glacier expansion and the 'elevation effect,' Karakoram Himalaya. Mt. Res. Dev., 25, 332-340, https://doi.org/10.1659/0276-4741(2005) 025[0332:TKAGEA]2.0.CO;2.

, 2007: Tributary glacier surges: an exceptional concentration at Panmah Glacier, Karakoram Himalaya. J. Glaciol., 53, 181-188, https://doi.org/10.3189/172756507782202829. 
- 2011: Glacier change, concentration, and elevation effects in the Karakoram Himalaya, Upper Indus Basin. Mt. Res. Dev., 31, 188-200, https://doi.org/10.1659/MRD-JOURNAL-D11-00020.1.

_- 2014: Glaciers of the Karakoram Himalaya: Glacial Environments, Processes, Hazards and Resources. Springer, $363 \mathrm{pp}$

Hock, R., and B. Holmgren, 2005: A distributed surface energybalance model for complex topography and its application to Storglaciären, Sweden. J. Glaciol., 51, 25-36, https://doi.org/ 10.3189/172756505781829566.

$\mathrm{Hu}, \mathrm{Z}$., and D. Chen, 2018: Evaluation of three global gridded precipitation data sets in central Asia based on rain gauge observations. Int. J. Climatol., 38, 1-19, https://doi.org/10.1002/ JOC.5510.

— , Q. Hu, C. Zhang, X. Chen, and Q. Li, 2016: Evaluation of reanalysis, spatially interpolated and satellite remotely sensed precipitation data sets in central Asia. J. Geophys. Res., 121, 5648-5663, https://doi.org/10.1002/2016JD024781.

Huffman, G. J., and Coauthors, 2007: The TRMM Multisatellite Precipitation Analysis (TMPA): Quasi-global, multiyear, combined-sensor precipitation estimates at fine scales. J. Hydrometeor., 8, 38-55, https://doi.org/10.1175/JHM560.1.

, R. F. Adler, D. T. Bolvin, and E. J. Nelkin, 2010: The TRMM Multi-satellite Precipitation Analysis (TMPA). Satellite Rainfall Applications for Surface Hydrology, M. Gebremichael and F. Hossain, Springer, 3-22, https://doi.org/10.1007/978-90481-2915-7_1.

— , and D. T. Bolvin, 2015: TRMM and other data precipitation data set documentation. NASA TRMM Doc., 44 pp., http:// pmm.nasa.gov/sites/default/files/imce/3B42_3B43_doc_V7.pdf.

Immerzeel, W. W., P. Droogers, S. M. de Jong, and M. F. P. Bierkens, 2009: Large-scale monitoring of snow cover and runoff simulation in Himalayan river basins using remote sensing. Remote Sens. Environ., 113, 40-49, https://doi.org/ 10.1016/j.rse.2008.08.010.

- L. P. van Beek, and M. F. Bierkens, 2010: Climate change will affect the Asian water towers. Science, 328, 1382-1385, https:// doi.org/10.1126/science.1183188.

—_, F. Pellicciotti, and A. B. Shrestha, 2012: Glaciers as a proxy to quantify the spatial distribution of precipitation in the Hunza Basin. Mt. Res. Dev., 32, 30-38, https://doi.org/ 10.1659/MRD-JOURNAL-D-11-00097.1.

- L. Petersen, S. Ragettli, and F. Pellicciotti, 2014: The importance of observed gradients of air temperature and precipitation for modeling runoff from a glacierized watershed in the Nepalese Himalayas. Water Resour. Res., 50, 2212-2226, https://doi.org/10.1002/2013WR014506.

— , N. Wanders, A. F. Lutz, J. M. Shea, and M. F. P. Bierkens, 2015: Reconciling high-altitude precipitation in the upper Indus basin with glacier mass balances and runoff. Hydrol. Earth Syst. Sci., 19, 4673-4687, https://doi.org/10.5194/hess-19-4673-2015.

Inman, M., 2010: Settling the science on Himalayan glaciers. Nat. Climate Change, 1, 28-30, https://doi.org/10.1038/ climate.2010.19.

Kääb, A., E. Berthier, C. Nuth, J. Gardelle, and Y. Arnaud, 2012: Contrasting patterns of early twenty-first-century glacier mass change in the Himalayas. Nature, 488, 495-498, https://doi.org/ 10.1038/nature11324.

, D. Treichler, C. Nuth, and E. Berthier, 2015: Brief communication: Contending estimates of 2003-2008 glacier mass balance over the Pamir-Karakoram-Himalaya. Cryosphere, $\mathbf{9}$, 557-564, https://doi.org/10.5194/tc-9-557-2015.
Khan, A., and M. Koch, 2018: Correction and informed regionalization of precipitation data in a high mountainous region (upper Indus basin) and its effect on SWAT-modelled discharge. Water, 10, 1557, https://doi.org/10.20944/ preprints201809.0241.v1.

_ - B. S. Naz, and L. C. Bowling, 2015: Separating snow, clean and debris covered ice in the Upper Indus Basin, HindukushKarakoram-Himalayas, using Landsat images between 1998 and 2002. J. Hydrol., 521, 46-64, https://doi.org/10.1016/ j.jhydrol.2014.11.048.

_ M. Koch, and K. Chinchilla, 2018: Evaluation of gridded multi-satellite precipitation estimation (TRMM-3B42-V7) performance in the Upper Indus Basin (UIB). Climate, 6 , 76-76, https://doi.org/10.3390/cli6030076.

Khan, S. I., Y. Hong, J. J. Gourley, M. U. K. Khattak, B. Yong, and H. J. Vergara, 2014: Evaluation of three high-resolution satellite precipitation estimates: Potential for monsoon monitoring over Pakistan. Adv. Space Res., 54, 670-684, https:// doi.org/10.1016/j.asr.2014.04.017.

Li, J., and A. D. Heap, 2011: A review of comparative studies of spatial interpolation methods in environmental sciences: Performance and impact factors. Ecol. Inform., 6, 228-241, https://doi.org/10.1016/j.ecoinf.2010.12.003.

Luo, Y., J. Arnold, S. Liu, X. Wang, and X. Chen, 2013: Inclusion of glacier processes for distributed hydrological modeling at basin scale with application to a watershed in Tianshan Mountains, northwest China. J. Hydrol., 477, 72-85, https:// doi.org/10.1016/j.jhydrol.2012.11.005.

Lutz, A. F., W. W. Immerzeel, and P. D. A. Kraaijenbrink, 2014a: Gridded meteorological datasets and hydrological modelling in the Upper Indus Basin. FutureWater Rep. 130, 83 pp., https://www.futurewater.nl/wp-content/uploads/2014/12/ UIB_Final_report_v3.pdf.

,-- B. Shrestha, and M. F. P. Bierkens, 2014b: Consistent increase in High Asia's runoff due to increasing glacier melt and precipitation. Nat. Climate Change, 4, 587-592, https:// doi.org/10.1038/nclimate2237.

, P. D. A. Kraaijenbrink, A. B. Shrestha, and M. F. P. Bierkens, 2016: Climate change impacts on the upper Indus hydrology: Sources, shifts and extremes. PLOS ONE, 11, e0165630, https://doi.org/10.1371/journal.pone.0165630.

Ma, L., T. Zhang, O. W. Frauenfeld, B. Ye, D. Yang, and D. Qin, 2009: Evaluation of precipitation from the ERA-40, NCEP-1, and NCEP-2 Reanalyses and CMAP-1, CMAP-2, and GPCP-2 with ground-based measurements in China. J. Geophys. Res., 114, D09105, https://doi.org/10.1029/2008JD011178.

Maggioni, V., P. C. Meyers, and M. D. Robinson, 2016: A review of merged high-resolution satellite precipitation product accuracy during the Tropical Rainfall Measuring Mission (TRMM) Era. J. Hydrometeor., 17, 1101-1117, https://doi.org/ 10.1175/JHM-D-15-0190.1.

Maussion, F., D. Scherer, T. Mölg, E. Collier, J. Curio, and R. Finkelnburg, 2014: Precipitation seasonality and variability over the Tibetan Plateau as resolved by the high Asia reanalysis. J. Climate, 27, 1910-1927, https://doi.org/10.1175/ JCLI-D-13-00282.1.

Mayer, C., A. Lambrecht, H. Oerter, M. Schwikowski, E. Vuillermoz, N. Frank, and G. Diolaiuti, 2014: Accumulation studies at a high elevation glacier site in central Karakoram. Adv. Meteor., 2014, 1-12, https://doi.org/ $10.1155 / 2014 / 215162$

Mendoza, P. A., M. P. Clark, N. Mizukami, E. D. Gutmann, J. R. Arnold, L. D. Brekke, and B. Rajagopalan, 2016: How do 
hydrologic modeling decisions affect the portrayal of climate change impacts? Hydrol. Processes, 30, 1071-1095, https:// doi.org/10.1002/hyp.10684.

Mishra, V., 2015: Climatic uncertainty in Himalayan water towers. J. Geophys. Res. Atmos., 120, 2689-2705, https:// doi.org/10.1002/2014JD022650.

Mölg, T., F. Maussion, and D. Scherer, 2014: Mid-latitude westerlies as a driver of glacier variability in monsoonal High Asia. Nat. Climate Change, 4, 68-73, https://doi.org/10.1038/ nclimate2055.

Mukhopadhyay, B., and A. Khan, 2014: A quantitative assessment of the genetic sources of the hydrologic flow regimes in Upper Indus Basin and its significance in a changing climate. J. Hydrol., 509, 549-572, https://doi.org/10.1016/ j.jhydrol.2013.11.059.

Palazzi, E., J. von Hardenberg, and A. Provenzale, 2013: Precipitation in the Hindu-Kush Karakoram Himalaya: Observations and future scenarios. J. Geophys. Res. Atmos., 118, 85-100, https://doi.org/10.1029/2012JD018697.

Pang, H., S. Hou, S. Kaspari, and P. A. Mayewski, 2014: Influence of regional precipitation patterns on stable isotopes in ice cores from the central Himalayas. Cryosphere, 8, 289-301, https://doi.org/10.5194/tc-8-289-2014.

Prein, A. F., and Coauthors, 2016: Precipitation in the EUROCORDEX $0.11^{\circ}$ and $0.44^{\circ}$ simulations: High resolution, high benefits? Climate Dyn., 46, 383-412, https://doi.org/10.1007/ s00382-015-2589-y.

Pritchard, H. D., 2017: Asia's glaciers are a regionally important buffer against drought. Nature, 545, 169-174, https://doi.org/ 10.1038/nature22062.

Putkonen, J. K., 2004: Continuous snow and rain data at 500 to $4400 \mathrm{~m}$ altitude near Annapurna, Nepal, 1999-2001. Arct. Antarct. Alp. Res., 36, 244-248, https://doi.org/10.1657/ 1523-0430(2004)036[0244:CSARDA]2.0.CO;2.

Ragettli, S., and F. Pellicciotti, 2012: Calibration of a physically based, spatially distributed hydrological model in a glacierized basin: On the use of knowledge from glaciometeorological processes to constrain model parameters. Water Resour. Res., 48, W03509, https://doi.org/10.1029/ 2011WR010559.

Raimonet, M., L. Oudin, V. Thieu, M. Silvestre, R. Vautard, C. Rabouille, and P. Le Moigne, 2017: Evaluation of gridded meteorological datasets for hydrological modeling. J. Hydrometeor., 18, 3027-3041, https://doi.org/10.1175/ JHM-D-17-0018.1.

Rasmussen, R., and Coauthors, 2012: How well are we measuring snow: The NOAA/FAA/NCAR winter precipitation test bed. Bull. Amer. Meteor. Soc., 93, 811-829, https://doi.org/10.1175/ BAMS-D-11-00052.1.

Reggiani, P., and T. H. M. Rientjes, 2015: A reflection on the longterm water balance of the Upper Indus Basin. Hydrol. Res., 46 , 446-462, https://doi.org/10.2166/nh.2014.060.

Renard, B., D. Kavetski, G. Kuczera, M. Thyer, and S. W. Franks, 2010: Understanding predictive uncertainty in hydrologic modeling: The challenge of identifying input and structural errors. Water Resour. Res., 46, W05521, https://doi.org/10.1029/ 2009WR008328.

Saha, S., and Coauthors, 2010: The NCEP Climate Forecast System Reanalysis. Bull. Amer. Meteor. Soc., 91, 1015-1058, https:// doi.org/10.1175/2010BAMS3001.1.

Salio, P., M. P. Hobouchian, Y. García Skabar, and D. Vila, 2015: Evaluation of high-resolution satellite precipitation estimates over southern South America using a dense rain gauge network. Atmos. Res., 163, 146-161, https://doi.org/10.1016/ j.atmosres.2014.11.017.

Scheel, M. L. M., M. Rohrer, C. Huggel, D. Santos Villar, E. Silvestre, and G. J. Huffman, 2011: Evaluation of TRMM Multi-satellite Precipitation Analysis (TMPA) performance in the Central Andes region and its dependency on spatial and temporal resolution. Hydrol. Earth Syst. Sci., 15, 2649-2663, https://doi.org/10.5194/hess-15-2649-2011.

Scherler, D., B. Bookhagen, and M. R. Strecker, 2011: Spatially variable response of Himalayan glaciers to climate change affected by debris cover. Nat. Geosci., 4, 156, https://doi.org/ 10.1038/ngeo1068.

Sheffield, J., G. Goteti, and E. F. Wood, 2006: Development of a 50-year high-resolution global dataset of meteorological forcings for land surface modeling. J. Climate, 19, 3088-3111, https://doi.org/10.1175/JCLI3790.1.

Sieck, L. C., S. J. Burges, and M. Steiner, 2007: Challenges in obtaining reliable measurements of point rainfall. Water Resour. Res., 43, W01420, https://doi.org/10.1029/ 2005WR004519.

Stisen, S., A. L. Højberg, L. Troldborg, J. C. Refsgaard, B. S. B. Christensen, M. Olsen, and H. J. Henriksen, 2012: On the importance of appropriate precipitation gauge catch correction for hydrological modelling at mid to high latitudes. Hydrol. Earth Syst. Sci., 16, 4157-4176, https://doi.org/10.5194/ hess-16-4157-2012.

Sun, Q., C. Miao, Q. Duan, H. Ashouri, S. Sorooshian, and K.-L. Hsu, 2018: A review of global precipitation data sets: Data sources, estimation, and intercomparisons. Rev. Geophys., 56, 79-107, https://doi.org/10.1002/2017RG000574.

Turc, L., 1954: Le bilan d'eau des sols: Relations entre les precipitations, l'evaporation et l'ecoulement. Ann. Agron., 5, 491-595.

Tuinenburg, O. A., R. W. A. Hutjes, and P. Kabat, 2012: The fate of evaporated water from the Ganges basin. J. Geophys. Res., 117, D01107, https://doi.org/10.1029/2011JD016221.

Tustison, B., D. Harris, and E. Foufoula-Georgiou, 2001: Scale issues in verification of precipitation forecasts. J. Geophys. Res., 106, 11 775-11 784, https://doi.org/10.1029/2001JD900066.

Valéry, A., V. Andréassian, and C. Perrin, 2010: Regionalization of precipitation and air temperature over high-altitude catchments - Learning from outliers. Hydrol. Sci. J., 55, 928-940, https://doi.org/10.1080/02626667.2010.504676.

Wagnon, P., and Coauthors, 2013: Seasonal and annual mass balances of Mera and Pokalde glaciers (Nepal Himalaya) since 2007. Cryosphere, 7,1769-1786, https://doi.org/10.5194/ tc-7-1769-2013.

Wake, C. P., 1989: Glaciochemical investigations as a tool to determine the spatial variation of snow accumulation in the Central Karakoram, Northern Pakistan. Ann. Glaciol., 13, 279-284, https://doi.org/10.3189/S0260305500008053.

Wang, B., and H. Lin, 2002: Rainy season of the Asian-Pacific summer monsoon. J. Climate, 15, 386-398, https://doi.org/ 10.1175/1520-0442(2002)015<0386:RSOTAP $>2.0$.CO;2.

Wang, X., Y. Zhang, Y. Luo, L. Sun, and M. Shafeeque, 2018: Combined use of volume-area and volume-length scaling relationships in glacio-hydrological simulation. Hydrol. Res., 49, 1753-1772, https://doi.org/10.2166/nh.2018.137.

Ward, E., W. Buytaert, L. Peaver, and H. Wheater, 2011: Evaluation of precipitation products over complex mountainous terrain: A water resources perspective. $A d v$. Water Resour., 34, 1222-1231, https://doi.org/10.1016/ j.advwatres.2011.05.007. 
Wei, J., P. A. Dirmeyer, D. Wisser, M. G. Bosilovich, and D. M. Mocko, 2013: Where does the irrigation water go? An estimate of the contribution of irrigation to precipitation using MERRA. J. Hydrometeor., 14, 275-289, https://doi.org/ 10.1175/JHM-D-12-079.1.

Winiger, M., M. Gumpert, and H. Yamout, 2005: KarakorumHindukush-western Himalaya: Assessing high-altitude water resources. Hydrol. Processes, 19, 2329-2338, https://doi.org/ 10.1002/hyp.5887.

Wortmann, M., T. Bolch, C. Menz, J. Tong, and V. Krysanova, 2018: Comparison and correction of high-mountain precipitation data based on glacio-hydrological modeling in the Tarim River headwaters (High Asia). J. Hydrometeor., 19, 777-801, https://doi.org/10.1175/JHM-D-17-0106.1.
Xu, B., P. Xie, M. Xu, L. Jiang, C. Shi, and R. You, 2015: A validation of passive microwave rain-rate retrievals from the Chinese FengYun-3B satellite. J. Hydrometeor., 16, 1886-1905, https://doi.org/10.1175/JHM-D-14-0143.1.

Yatagai, A., K. Kamiguchi, O. Arakawa, A. Hamada, N. Yasutomi, and A. Kitoh, 2012: APHRODITE: Constructing a longterm daily gridded precipitation dataset for Asia based on a dense network of rain gauges. Bull. Amer. Meteor. Soc., 93, 1401-1415, https://doi.org/10.1175/BAMS-D11-00122.1.

Zhao, T., and C. Fu, 2006: Comparison of products from ERA-40, NCEP-2, and CRU with station data for summer precipitation over China. Adv. Atmos. Sci., 23, 593-604, https://doi.org/ 10.1007/s00376-006-0593-1. 